University of São Paulo

School of Economics, Business Administration and Accounting at Ribeirão Preto

Department of Economics

Postgraduate Program in Economics - Area: Applied Economics

Eduardo Teixeira de Carvalho Silva

Risk sharing in the Brazilian regional case

Supervisor: Alex Luiz Ferreira

Ribeirão Preto

2020 
Prof. Dr. Vahan Agopyan

Rector of University of São Paulo

Prof. Dr. André Lucirton Costa

Director of School of Economics, Business Administration and Accounting at Ribeirão Preto

Prof. Dr. Sérgio Kannebley Junior

Head of Economics Department

Prof. Dr. Sérgio Naruhiko Sakurai

Coordinator of Graduate Program in Economics - Area: Applied Economics 
Eduardo Teixeira de Carvalho Silva

\section{Risk sharing in the Brazilian regional case}

Dissertation presented to Postgraduate Program in Economics - Area: Applied Economics in the

School of Economics, Business Administration and Accounting at Ribeirão Preto of University of São Paulo to obtain a Master's degree.

Supervisor: Alex Luiz Ferreira

Versão Corrigida. A original encontra-se disponível na FEA-RP/USP.

Ribeirão Preto

2020 
I authorize the total or partial reproduction and disclosure of this work, by any conventional or electronic mean, for study and research purposes, provided that the source is mentioned.

Part of this dissertation belongs to a paper written in co-authorship with Dr. Alex Luiz Ferreira preliminary entitled "Risk Sharing within Brazil and the Mercosul"

\author{
Silva, Eduardo Teixeira de Carvalho \\ Risk Sharing In The Brazilian Regional Case . Ribeirão Preto, 2020 \\ 80p. : il. ; $30 \mathrm{~cm}$ \\ Dissertação de Mestrado, apresentada à Faculdade de Economia, Administração e Con- \\ tabilidade de Ribeirão Preto/USP. Área: Economia Aplicada . \\ Orientador - Prof. Dr. Alex Luiz Ferreira
}

1. Compartilhamento de Risco. 2. Macroeconomia Regional. 3. Federalismo fiscal. I. Orientador: Prof. Dr. Alex Luiz Ferreira. II. Universidade De São Paulo - Campus Ribeirão Preto. III. Faculdade de Economia, Administração e Contabilidade de Ribeirão Preto. IV. Compartilhamento de risco no caso regional brasileiro. 


\section{Acknowledgements}

I would like to thank my supervisor, professor Alex Ferreira, for the helpful guidance and patience during the process of writing this dissertation.

I also would like to thank all the professors that supported me so far and shared knowledge during my graduation and my master's. I would like to mention professor Sérgio Sakurai for all the assistance given me until then and professor Roseli Silva, which supervised me during my graduation. I also want to thank professors Eliezer Diniz and Fabio Gomes for the insights given during the qualification and pre-defense exams.

I also want to express my gratitude to professor Miguel León-Ledesma for having me at the University of Kent and for the insights given regarding my dissertation.

I also would like to thank my family and friends for all the companionship and support.

This study was financed in part by the Coordenação de Aperfeiçoamento de Pessoal de Nível Superior - Brasil (CAPES) - Finance Code 001 


\begin{abstract}
Silva, E. T. C. Risk sharing in the Brazilian regional case. School of Economics, Business Administration and Accounting at Ribeirão Preto, University of São Paulo, Ribeirão Preto, 2020.

The goal of this dissertation is to evaluate in which degree and how the consumption risk sharing is achieved among Brazilian states. The main result of consumption risk sharing theory entails that if all the consumption risk sharing opportunities are explored, consumption on regional and aggregate levels should be perfect correlated and individual income variations have no effect on consumption. At first place, this study sought to analyze in which degree the Brazilian states consumption is related to the country level. The results for the regional case are then compared to the international, in order to examine if the reduced number of barriers within the states encourages risk sharing, as is pointed at empirical literature on the area. Lastly, this research explores what is the role of fiscal federalism as a stabilizer, analyzing from taxes and transfers data in which degree the state income volatility is reduced by the federal government. The results point to an elevated degree of consumption integration among the Brazilian states, while the country presents a lower degree of risk sharing with its neighbor countries. Besides that, the results suggests that fiscal federalism acts as a stabilizer of state income, reducing around $13 \%$ the effect of idiosyncratic shocks.
\end{abstract}

Keywords: Risk Sharing; Regional Macroeconomics; Fiscal Federalism.

JEL Code: F40; H77; R10. 


\section{Resumo}

Silva, E. T. C. Compartilhamento de risco no caso regional brasileiro. Faculdade de Economia, Administração e Contabilidade de Ribeirão Preto, Universidade de São Paulo, Ribeirão Preto, 2020.

Este trabalho tem como objetivo analisar em que grau e como se dá o compartilhamento de risco de consumo entre os estados brasileiros. O principal resultado da teoria de compartilhamento de risco de consumo prega, que quando todas as oportunidades de compartilhamento de risco são exploradas, o consumo de cada região deve ser perfeitamente correlacionado com o consumo agregado, de modo que choques regionais não afetam o nível de consumo. Inicialmente, este estudo buscou analisar em que grau o consumo dos estados brasileiros está relacionado com o nível do país. Os resultados para o nível regional foram então comparados ao nível internacional, de forma a analisar se o menor número de barreiras dentro do país incentiva o compartilhamento de risco, conforme é apontado pela literatura empírica. Por fim, este trabalho explora qual é o papel do federalismo fiscal como estabilizador, analisando, a partir de dados de tributação e repasses, em que grau o governo federal reduz a volatilidade da renda dos estados. Os resultados apontaram para um elevado grau de integração entre o consumo dos estados brasileiros, enquanto o país apresenta um mais baixo nível de compartilhamento de risco com seus países vizinhos. Além disso, os resultados sugerem que o federalismo fiscal atua como estabilizador da renda dos estados, reduzindo por volta de $13 \%$ dos choques idiossincráticos.

Palavras-chaves: Compartilhamento de Risco. Macroeconomia Regional. Federalismo Fiscal.

JEL Code: F40; H77; R10. 


\section{Contents}

\begin{tabular}{lll}
\hline 1 & Introduction & 12
\end{tabular}

2 Modeling Incomplete Risk Sharing $\quad 15$

2.1 Theoretical Framework . . . . . . . . . . . . . . . . . . . . . . . . . . . . . . 16

2.1 .1 Crucini $\mathrm{s}(1999)$ Incomplete Risk Sharing Model . . . . . . . . . . . 16

2.1.2 Asdrubali and Kim $[(2008)$ Incomplete Intertemporal Smoothing Model 18

2.2 Data and Descriptive Statistics $\ldots \ldots \ldots \ldots \ldots \ldots$

$2.2 .1 \quad$ Data Details . . . . . . . . . . . . . . . . . 20

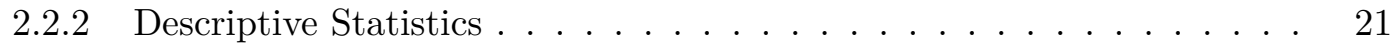

2.3 Methodology and Results . . . . . . . . . . . . . . . . . . . . . . . . . 24

$2.3 .1 \quad$ Crucinils $(1999)$ model . . . . . . . . . . . . . . . . 24

2.3 .2 Asdrubali and Kim s $(2008)$ model . . . . . . . . . . . . . . . 32

\begin{tabular}{|lll}
\hline 3 & The Role of Fiscal Federalism on Brazilian Risk Sharing & 36
\end{tabular}

$3.1 \quad$ Fiscal Centralization as a Source of Risk Sharing . . . . . . . . . . . . . . . 36

3.2 Theoretical Framework . . . . . . . . . . . . . . . . . . . . . . . . . . . . . 38

3.2 .1 Sala-i Martin and Sachs s (1991) Approach . . . . . . . . . . . . . 38

3.2 .2 Asdrubali et al. s (1996) Variance Decomposition Approach . . . . . . 40

3.3 Brazilian Taxes and Transfers Data . . . . . . . . . . . . . . . . . . . 42

3.4 Methodology and Results . . . . . . . . . . . . . . . . . . . . 48

3.4 .1 Sala-i Martin and Sachs $(1991)$ Model . . . . . . . . . . . . . . . 48

3.4 .2 Asdrubali et al. s (1996) Model Estimation Results . . . . . . . . . . . 53

\begin{tabular}{lll}
\hline & Final Remarks & 55
\end{tabular}

A Derivation of Crucini's (1999) and Asdrubali and Kim's (2008) Risk Shar$\begin{array}{lc}\text { ing Equations } & 60\end{array}$

A.1 Crucinils (1999) Risk Sharing Equation . . . . . . . . . . . . . . 60

A.2 Asdrubali and Kim $\mid \mathrm{s}(2008)$ Risk Sharing Equation . . . . . . . . . . . . . 62

B Demonstration of the permanent income revision rule for the VAR(1) case 63

\begin{tabular}{ll}
\hline C Data and Sources & 65
\end{tabular} 
D Crucini's (1999) Model State Estimates

66 


\section{List of Figures}

$1 \quad$ Real net transfers per Brazilian state on $2002 \ldots \ldots \ldots$. . . . . . . . . 44

2 Real net transfers per Brazilian state on 2019 . . . . . . . . . . . . . 45 


\section{List of Tables}

$1 \quad$ Descriptive statistics for yearly income and consumption data . . . . . . . . . 22

$2 \quad$ Descriptive statistics for MERCOSUL countries yearly per capita income and

consumption data . . . . . . . . . . . . . . . . . . . 23

$3 \quad \mathrm{AR}(1)$ income specification estimation results $\ldots \ldots \ldots \ldots \ldots$

$4 \quad \mathrm{VAR}(1)$ income specification estimation results $\ldots \ldots \ldots \ldots$. . . . . . 28

5 State level risk sharing coefficient estimates $\ldots \ldots \ldots \ldots$

$6 \quad$ Equation (10) panel OLS estimates . . . . . . . . . . . . . . . . 30

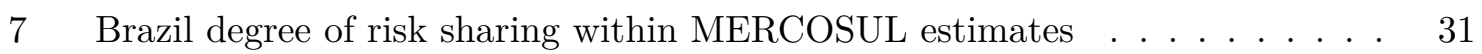

$8 \quad$ IV panel estimation results of equation $(21) \ldots \ldots \ldots \ldots$

$9 \quad$ Diagnostic tests of equation (21) panel IV estimation . . . . . . . . . . . . . . 34

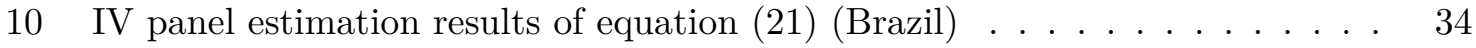

11 Diagnostic tests of equation (21) panel IV estimation (Brazil) . . . . . . . . . 35

12 Transfers and tax revenue relative to state income . . . . . . . . . . . . 46

$13 \quad$ Per capita transfers and tax revenue per Brazilian state . . . . . . . . . . . . 47

14 Tax elasticities . . . . . . . . . . . . . . . . . . . . . . . . . 49

15 Transfers elasticities $\ldots \ldots \ldots \ldots \ldots$. . . . . . . . . . . . . . 49

16 Transfers elasticities estimation with state fixed effects . . . . . . . . . . . . 50

17 Effect of net fiscal transfers on the regional disposable income . . . . . . . . . 52

18 Effect of Net Fiscal Transfers on the Regional Disposable Income . . . . . . . 54

19 Raw data details $\ldots \ldots \ldots \ldots \ldots \ldots \ldots$

$20 \quad$ Augmented Dickey-Fuller unit root test for Brazilian state product . . . . . . 67

21 Augmented Dickey-Fuller unit root test for MERCOSUL countries product . 68

$22 \quad \mathrm{AR}(1)$ estimates for Brazilian state product $\ldots \ldots \ldots \ldots \ldots$

23 AR(1) estimates for MERCOSUL countries per capita gross domestic product 70

$24 \quad \operatorname{VAR}(1)$ estimates for per capita Brazilian states product $\left(A^{21}\right) \ldots \ldots$. . . 71

$25 \quad \operatorname{VAR}(1)$ estimates for per capita Brazilian states product $\left(A^{22}\right)$. . . . . . . 72

$26 \quad \operatorname{VAR}(1)$ estimation for MERCOSUL country level data $\left(A^{21}\right) \ldots \ldots \ldots . . . \quad 73$

$27 \quad \operatorname{VAR}(1)$ estimation for MERCOSUL country level data $\left(A^{22}\right) \ldots \ldots$. . . . . 73

28 Degree of risk sharing estimates assuming a RW as income process for Brazilian

states . . . . . . . . . . . . . . . . . . . . 74 
29 Degree of risk sharing estimates assuming an AR(1) as income process for Brazilian states . . . . . . . . . . . . . . . . . . . . . 75

30 Degree of Risk sharing Estimates assuming a VAR(1) as income process for Brazilian states . . . . . . . . . . . . . . . . . . . . . 76

31 Degree of Risk sharing Estimates assuming a RW as income process for MERCOSUL countries . . . . . . . . . . . . . . . . . . . . . . . . 77

32 Degree of Risk sharing Estimates assuming a $\mathrm{AR}(1)$ as income process for MERCOSUL countries . . . . . . . . . . . . . . . . . . . . . . . . . . . . 77

33 Degree of Risk sharing Estimates assuming a VAR(1) as income process for MERCOSUL countries . . . . . . . . . . . . . . . . . . 78 


\section{Introduction}

Individuals are often modeled as risk averse in economic theory, which is explained by a diminishing marginal utility of wealth. It implies that agents prefer to trade off a share of their income for a reduction in consumption uncertainty. A corollary of this assumption is that there is a market mechanism that transfers funds from agents hit by favorable shocks to the ones hit by adverse shocks, thus reducing consumption volatility.

This idea is put forward by Arrow (1973) and Debreu (1959) in their Standard Complete Markets (SCM) Model. Their main result is that asset markets allow agents to share their risks related to idiosyncratic income uncertainty. Although this result requires the existence of a complete assets market, the same allocation could be achieved by a social planner under certain conditions.

Aggregate income levels are volatile and systemic country risks cannot be shared in a closed economy. However, the existence of complete financial markets allow agents to share all idiosyncratic risks between them in the open economy, an arrangement known as perfect risk sharing. It follows that the SCM model can also be applied to an international macroeconomic set up by, for example, considering countries or regions as the "microeconomic" agents of the model.

Seminal papers in this area like Crucini (1999) and Crucini and Hess (2000) examined the extent of risk sharing between countries. Most of them point out to a low degree of risk sharing rejecting the prediction of the theory. One possible explanation for this failure is the so-called border effects. It is believed that political and cultural differences, taxes, transaction costs, among other factors, limit the extent to which risk is shared between countries.

The intranational case is interesting because there are much less barriers for integration within a country then between nations. This could be seen as a benchmark case for countries that are planning for a higher degree of market integration. However, if the results between the international and intranational cases do not differ substantially, there must be other explanations for the reduced degree of risk sharing.

Over time, the literature has evolved to identify the role of each mechanism through which countries and regions have shared their consumption risks. Capital and credit markets are two of the main channels of risk sharing, as they allow agents to borrow and lend resources and the cross-ownership of assets from other countries and regions that are exposed to different risks. Another important channel is fiscal tax-transfer mechanism, as a central 
government has the power to move income between regions in order to reduce its volatility. Papers like Asdrubali et al. (1996) and Athanasoulis and Wincoop (2001) indicates that the fiscal transfers system plays a smaller role on risk sharing then credit and capital markets for the United States regional case.

There is an extensive literature examining the degree of intranational risk sharing, such as Van Wincoop (1995), Asdrubali and Kim (2008) and Athanasoulis and Wincoop (2001). Most papers are focused on developed countries, e.g., United States, Japan and Canada. Due to absence of data, there are fewer studies examining risk sharing for emerging economies, and most papers in this part of the literature are concentrated on the Chinese case, for example Du et al. (2011) and Ho et al. (2015). The empirical evidence shows that federal integration helps to smooth idiosyncratic risks in the USA 1 pointing to welfare gains. As mentioned above, examine this subject empirically may be a challenge on developing countries as the data available could be poor at a regional or more disaggregated level. However, this is an issue that worth exploring as there may be unexplored risk sharing opportunities, which is a scope for social welfare increase.

In light of the benefits of consumption risk sharing, our main contribution is to estimate the intranational degree of risk sharing for the Brazilian case, a subject that was not much explored so far due to the absence of data on the past years. Another contribution of this study is to examine the role of Brazilian fiscal federalism on income volatility cushioning. Most of the procedures on this literature relies on consumption data. From 2000 onward, Instituto Brasileiro de Geografia e Estatística (IBGE) started providing state level retail sales data, which is a reliable consumption proxy. This data enables the empirical analysis of risk sharing at Brazilian regional level that requires consumption data.

Estimating the degree of risk sharing for Brazil and measuring the role of each channel would allow us to examine the extent to which there is more room for both country intranational and international integration. This could be useful to suggest economic policies to improve the society's overall welfare, as the results may be used to analyze if capital and financial markets need better development or if the government is not succeeding on reducing the regional income volatility.

The remainder of this work is organized in three chapters. Chapter 2 is based on models that estimates the overall degree of risk sharing, following Crucinils (1999) framework. Chapter 3 focus on the role of fiscal federalism on Brazilian regional risk sharing, while the

\footnotetext{
${ }^{1}$ See Parsley and Popper (2018), Feyrer and Sacerdote (2013) and Athanasoulis and Wincoop (2001)
} 
final chapter presents our concluding remarks and policy suggestions. 


\section{Modeling Incomplete Risk Sharing}

The main implication of the theory of risk sharing is that individual consumption varies in response to aggregate risk instead of responding to idiosyncratic shocks. This means that if all risk sharing opportunities are explored, consumption on individual and aggregate levels move together and individual income variations have no effect on consumption.

Arrow (1973) and Debreu (1959) Standard Complete Markets (SCM) Model optimal equilibrium is defined as complete risk sharing. This allocation requires the absence of frictions and the existence of a complete asset market or a benevolent social planner, which proceeds with income transfers reducing its volatility.

An important characteristic of an allocation that delivers complete risk sharing is that individual consumption will be a constant share of aggregate income, not necessarily equal to each agent, and that depends on individual income distribution. This implies that personal and aggregate consumption move together. Based on this idea, some of the earliest papers on the field, e.g. Atkeson and Bayoumi (1993) have tested the null hypothesis of complete risk sharing for macroeconomic data. Studies in the area presented strong evidence against the hypothesis of complete risk sharing.

Perfect risk sharing is clearly a result that is only observed under stringent assumptions (such as the existence of complete markets and absence of transaction costs). In reality, due to frictions, agents choose different levels of risk sharing. Crucini (1999) recognizes the importance of imperfections and develops a model which allows for incomplete risk sharing.

This chapter proceeds with the estimation of the degree of risk sharing among Brazilian states relying on two different models of incomplete risk sharing. We first follow the framework of Crucinils (1999), and them we proceed with the estimation of Asdrubali and Kim (2008) model, which is an extension of the latter allowing for incomplete intertemporal smoothing over time.

As highlighted on Crucini (1999) and Crucini and Hess (2000) and in other literature regarding regional risk sharing, such as Atkeson and Bayoumi (1993) there is a higher degree of income smoothing within regions and states on countries in comparison to the international level. To examine if the same is valid for Brazil, we also estimate an incomplete risk sharing model for the countries that compose MERCOSUL, comparing then the results at the regional and international levels. A difference of results in favor of regional level suggests that the reduced barriers inside the country is useful to smooth idiosyncratic shocks, and also highlight 
the role of fiscal federalism on controlling regional consumption volatility.

After this introduction, section 2.1 presents the incomplete risk sharing models on which the empirical analysis is based. The next section describes the data used on the chapter estimations and shows some descriptive statistics, while the final section discusses the methodology and present the results.

\subsection{Theoretical Framework}

\subsubsection{Crucini's (1999) Incomplete Risk Sharing Model}

Crucinils $(1999)$ model is an adaptation of the permanent income hypothesis. In his model a region could sell a fraction of its income in exchange for a claim to the pooled income stream of all the regions. In this setup, a region $j$ sells a fraction $\lambda_{j}$ of its income $\left(Y_{j t}\right)$, in exchange for the same fraction $\lambda_{j}$ of the total amount in the pool, defined by $Y_{a t}=\frac{1}{\Lambda} \sum_{j=1}^{J} \lambda_{j} Y_{j t}$, with $\Lambda=\sum_{j=1}^{J} \lambda_{j}$. Within this model, the amount of income in period $t$ for region $j$ after risk sharing is defined as $\bar{Y}_{j t}$, which is given by $\bar{Y}_{j t}=\lambda_{j} Y_{a t}+\left(1-\lambda_{j}\right) Y_{j t}$.

Suppose that individuals apply the discount rate $\beta$ and can borrow and lend at the fixed real interest rate $r$ to smooth consumption 2 , and they follow a Friedman s (1957) permanent income theory decision rule for consumption. Notice it is assumed that agents are optimizers, and they adjust their consumption path accordingly to new information regarding their permanent incomes. We have then the following equation for consumption change, in which $C_{j t}$ represents the consumption of region $j$ representative agent:

$$
\Delta C_{j t}=(1-\beta) \sum_{k=0}^{\infty} \beta^{k}\left[\mathbb{E}_{t} \bar{Y}_{j t+k}-\mathbb{E}_{t-1} \bar{Y}_{j t+k}\right]
$$

where $\Delta$ represents the first difference of a variable and $\mathbb{E}$ represents its expectation.

Aggregating equation (1), taking the average and combining the result with the pooling equation, gives the following decision rule:

$$
\Delta C_{j t}=\lambda_{j} \Delta C_{a t}+\left(1-\lambda_{j}\right)(1-\beta) \sum_{k=0}^{\infty} \beta^{k}\left[\mathbb{E}_{t} Y_{j t+k}-\mathbb{E}_{t-1} Y_{j t+k}\right] .
$$

Note that the second element on the right side of the equation represents the forecast revision on the agents permanent income, and $C_{a t}$ denotes the aggregate consumption variation. Notice also that we assume $\Delta C_{a t} \equiv \frac{1}{J} \sum_{j=1}^{J} \Delta C_{j t}$, so the aggregate consumption variation is

\footnotetext{
${ }^{2}$ Notice that $0<\beta<1$ and $r$ is given by $r=\beta^{-1}-1$.
} 
the simple average of the growth rates of all agents. A formal derivation of equation (2) can be found at the Appendix A.

Until this point, we have been using the levels of consumption and income. Therefore, we will proceed with the estimations using the logarithm of consumption and income. The linearization of the model is the same as in Crucini (1999), and also the linearization of consumption will follow Campbell and Mankiw (1989). From this point on, lowercase letters will be used to denote the logarithm of the level of models variables.

Crucini (1999) estimates the following equation:

$$
\Delta c_{j t}=\lambda_{j} \Delta c_{a t}+\left(1-\lambda_{j}\right) \Delta \hat{y} p_{j t}+\epsilon_{j t}
$$

in which $\Delta \hat{y p} p_{j t}=(1-\beta) \sum_{k=0}^{\infty} \beta^{k}\left[\mathbb{E}_{t} Y_{j t+k}-\mathbb{E}_{t-1} Y_{j t+k}\right]$ is the forecast update from $t$ to $t-1$ on permanent income and $\epsilon_{j t}$ denotes the shock term ${ }^{3}$.

The equation above can be estimated in a two step regression. First, the expected changes in regional permanent income $\left(\hat{y p}_{j t}\right)$ are estimated and then equation (3) is estimated. An income process is assumed in order to forecast the permanent income in the first step. Crucini (1999) assumes three different income process, in order to check the sensibility of the results:

$$
\begin{gathered}
\left(\begin{array}{c}
\Delta y_{a t} \\
\Delta y_{j t}
\end{array}\right)=\left(\begin{array}{cc}
A_{j}^{11} & A_{j}^{12} \\
A_{j}^{21} & A_{j}^{22}
\end{array}\right)\left(\begin{array}{c}
\Delta y_{a t-1} \\
\Delta y_{j t-1}
\end{array}\right)+\left(\begin{array}{c}
v_{a j t} \\
v_{j t}
\end{array}\right), \\
\Delta y_{j t}=\theta_{j} \Delta y_{t-1}+v_{j t},
\end{gathered}
$$

Equation (4) assumes a joint process VAR(1) for the first difference of the log of aggregate and regional income. Equation (5) assumes $\Delta y_{j t}$ follows an $\mathrm{AR}(1)$ process and equation (6) assumes $y_{j t}$ follows a Random Walk.

In fact, there are two different possible ways to smooth consumption. The first is by sharing risk within individuals at a particular time, which is a form of intratemporal smoothing. The second is by reallocating consumption over time by borrowing and lending. This is known as intertemporal consumption smoothing and is related with the permanent income hypothesis. Note from equation (1) that the variation on consumption follows the revision

\footnotetext{
${ }^{3}$ The shock terms are independent and identically distributed.
} 
on permanent income, so Crucini (1999) assumes that Friedman's (1957) permanent income hypothesis holds fully. The empirical works usually focus on one or another possibility, i.e, risk sharing or intertemporal consumption smoothing, which requires a different hypothesis for each of them.

\subsubsection{Asdrubali and Kim (2008) Incomplete Intertemporal Smoothing Model}

Asdrubali and Kim (2008) develop a methodology that does not require any hypothesis about the level of intratemporal or intertemporal smoothing, allowing us to estimate it both ways. Their framework includes income pooling, as in Crucini (1999), but the permanent income hypothesis does not necessarily holds fully.

It is important to highlight in which manner intratemporal and intertemporal smoothing are two distinct things. The first is related to the income pooling, and is an ex ante form of smoothing, as it deals with the idiosyncratic shocks. Intertemporal smoothing relates to the way consumption is allocated over time in response to changes on permanent income, and is an ex post form os smoothing. As we will be able to see with the development of this section model, perfect risk sharing implies full intertemporal smoothing.

In this framework, we allow for imperfect intertemporal smoothing. Define $\gamma$ as the degree of intertemporal income smoothing, which assumes values between 0 and 1 . Perfect smoothing implies a $\gamma=1$, while the complete absence of it implies $\gamma=0$. Notice $\gamma$ is defined as the fraction of permanent income used to smooth consumption, while $1-\gamma$ is the proportion of disposable income that is consumed. The change in consumption is now given by equation (7), which is a variation of equation (1).

$$
\begin{gathered}
\Delta C_{j t}=\mu_{j}+\left(1-\gamma_{j}\right) \Delta \bar{Y}_{j t}+\gamma_{j} \bar{\epsilon}_{j t}, \\
\bar{\epsilon}_{j t} \equiv(1-\beta) \sum_{k=0}^{\infty} \beta^{k}\left[\mathbb{E}_{t} \bar{Y}_{j t+k}-\mathbb{E}_{t-1} \bar{Y}_{j t+k}\right] .
\end{gathered}
$$

Notice from equation (7) that when we have full intertemporal smoothing $(\gamma=1)$, all the variation on consumption comes from permanent income, while in the case with no interteporal smoothing $\gamma=0$ the variation on disposable income is fully translated into consumption.

As we have income pooling, disposable income is still given by $\bar{Y}_{j t}=\lambda_{j} Y_{a t}+(1-$ $\left.\lambda_{j}\right) Y_{j t}$. The equation (8) is the change in agents estimate of their permanent income from 
period $t$ to $t-1$. Following a procedure very similar to Crucini (1999), Asdrubali and Kim (2008) develop the following equation (also in log level), which demonstration is done in details on appendix A:

$$
\Delta c_{j t}=\overline{\mu_{j}}+\lambda_{j} \Delta c_{a t}+\left(1-\gamma_{j}\right)\left(1-\lambda_{j}\right) \Delta y_{j t}+\eta_{j t}
$$

where

$$
\begin{gathered}
\eta_{j t} \equiv \gamma_{j}\left(\bar{\epsilon}_{j t}-\lambda_{j} \epsilon_{j t}\right)=\gamma_{j}\left(1-\lambda_{j}\right) \epsilon_{j t}, \\
\overline{\mu_{j}}=\mu_{j}-\lambda \mu,
\end{gathered}
$$

and

$$
\epsilon_{j t}=(1-\beta) \sum_{k=0}^{\infty} \beta^{k}\left[\mathbb{E}_{t} y_{j t+k}-\mathbb{E}_{t-1} y_{j t+k}\right]
$$

This model allows us to jointly estimate the degree of risk sharing $(\lambda)$ and the degree of intertemporal consumption smoothing $(\gamma)$, as it permits different combinations of the coefficients. León-Ledesma and Mihailov (2010) bring up an interesting analysis of the implications of equation (9). If $\lambda$ and $\gamma$ are zero, the consumption changes are fully dependent on domestic income changes, which coincides with the traditional Keynesian consumption function. When we allow both parameters to increase, the consumption growth becomes more correlated with aggregate consumption changes and with shocks on permanent income.

In the case with full risk sharing but no intertemporal smoothing $(\lambda=1$ and $\gamma=0)$, individual consumption growth is perfectly correlated with aggregate consumption growth. However on the opposite case $(\lambda=0$ and $\gamma=1)$, consumption growth will depend only on shocks to permanent income. Finally, it is important to highlight that if it is assumed that $y_{j t}$ follows a pure random walk, all income shocks hit permanent income, and equation (9) will become:

$$
\Delta c_{j t}=\bar{\mu}_{j}+\lambda_{j} \Delta c_{a t}+\left(1-\lambda_{j}\right) \Delta y_{j t}
$$

and hence $\gamma$ would be irrelevant. León-Ledesma and Mihailov (2010)

It is relevant to emphasize that a great number of households in Brazil cannot 
"exactly" be defined as "Ricardians" or optimizes, in the sense that they cannot smooth out variations in income using financial markets. This concept was first described by Campbell and Mankiws s (1989) "rule of thumb behavior", in which a fraction of agents consume out of their permanent income instead of optimizing over time mostly due to credit restrictions. Oliveira and Carrasco-Gutierrez (2016) find in a recent study that a fraction from 0.48 to 0.54 of the consumers in Brazil follows a rule of thumb behavior. With that in mind, $\gamma$ could be interpreted then as the fraction of "rule of thumb" agents in the economy.

\subsection{Data and Descriptive Statistics}

In this section we describe the main features of data used to estimate the models presented on section 2.1. We also report and discuss some descriptive statistics of data on the following subsection. Further details of data are provided on the Appendix C.

\subsubsection{Data Details}

The models from section 2.1 are estimated both for the Brazilian states and for Mercado Comum do Sul (MERCOSUL) countries.

\section{State Level Data:}

Due to the absence of consumption data, we use Real Retail Sales Index as a consumption proxy. This index was collected from Instituto Brasileiro de Geografia e Estatística (IBGE) on a monthly frequency. This index was also collected for the aggregate level (Brazil). Real Gross State Product (GSP) data was taken from IBGE regional accounting system along with state price indexes, which were on a yearly basis. Population data for Brazil and Brazilian states were also collected from IBGE. Those data were used to transform both consumption and product into per capita terms.

Population and GSP data are on a yearly frequency, ranging form 1985 to 2017, while consumption is on a monthly frequency, ranging from 2000.01 to 2017.12. As we work with annual data, the retail sales index (consumption) was converted from monthly to yearly by taking the average of the index over the year, resulting on a variable ranging from 2000 to 2017. In order to convert the data in an index format to per capita terms, population data was also transformed into an index. 


\section{Country Level Data:}

The international data used was collected from the World Bank Open Data 4 The group of countries included on the database is composed of official and associate members of MERCOSUL, which are: Argentina, Bolivia, Brazil, Chile, Colombia, Ecuador, Paraguay, Peru and Uruguay 5. The database consists of three variables, which are population, final consumption expenditure and gross domestic product (GDP). Those last two variables are in constant 2010 US\$. As with state level data, population was used to convert the variables to per capita terms. The data is on a yearly frequency, and its range is from 1962-2018.

\subsubsection{Descriptive Statistics}

After converting the data into per capita terms, we used log-differences of consumption and income in what follows, resulting in growth rates of our variables. We then compute some descriptive statistics of our growth rate series, which are the standard deviation, correlation of consumption and income for each region, correlation with the aggregate level and with a reference region. We begin with the analysis of state level data, proceeding then to country level data.

\section{State Level Data:}

São Paulo was selected as the reference region, which is due to the economic size of this region. As mentioned on Crucini and Hess (2000), it is expected that the correlation with a reference region is lower than with the aggregate level, given that the regional variable is contained on the aggregate. The following table reports the statistics listed above for state level data. The last row of the table contains the standard deviation of income and consumption growth for the aggregate level as well as their correlation.

\footnotetext{
${ }^{4}$ https://data.worldbank.org/

${ }^{5}$ Guyana and Suriname were not included due to the absence of consumption data for those countries. Venezuela was also not included on the database the government stopped providing data for the most recent years.
} 
Table 1: Descriptive statistics for yearly income and consumption data

\begin{tabular}{|c|c|c|c|c|c|c|c|}
\hline State & $\mathbf{s d}\left(\Delta c_{j t}\right)$ & $\mathbf{s d}\left(\Delta y_{j t}\right)$ & $\rho\left(\Delta c_{B R t}, \Delta c_{j t}\right)$ & $\rho\left(\Delta y_{B R t}, \Delta y_{j t}\right)$ & $\rho\left(\Delta y_{j t}, \Delta c_{j t}\right)$ & $\rho\left(\Delta c_{S P t}, \Delta c_{j t}\right)$ & $\rho\left(\Delta y_{S P t}, \Delta y_{j t}\right)$ \\
\hline$A C$ & 0.093 & 0.035 & 0.807 & 0.623 & 0.641 & 0.699 & 0.653 \\
\hline$A L$ & 0.085 & 0.030 & 0.853 & 0.759 & 0.676 & 0.773 & 0.780 \\
\hline$A M$ & 0.077 & 0.042 & 0.718 & 0.847 & 0.699 & 0.551 & 0.759 \\
\hline$A P$ & 0.098 & 0.038 & 0.728 & 0.688 & 0.763 & 0.674 & 0.579 \\
\hline$B A$ & 0.070 & 0.036 & 0.947 & 0.855 & 0.804 & 0.850 & 0.773 \\
\hline$C E$ & 0.066 & 0.030 & 0.887 & 0.793 & 0.631 & 0.785 & 0.709 \\
\hline$D F$ & 0.061 & 0.021 & 0.826 & 0.707 & 0.809 & 0.694 & 0.732 \\
\hline$E S$ & 0.075 & 0.055 & 0.857 & 0.850 & 0.640 & 0.770 & 0.781 \\
\hline$G O$ & 0.073 & 0.032 & 0.822 & 0.916 & 0.717 & 0.734 & 0.861 \\
\hline$M A$ & 0.081 & 0.034 & 0.836 & 0.773 & 0.738 & 0.715 & 0.690 \\
\hline$M G$ & 0.046 & 0.034 & 0.885 & 0.914 & 0.761 & 0.823 & 0.859 \\
\hline$M S$ & 0.063 & 0.033 & 0.881 & 0.523 & 0.469 & 0.863 & 0.448 \\
\hline$M T$ & 0.082 & 0.053 & 0.726 & 0.574 & 0.847 & 0.702 & 0.554 \\
\hline$P A$ & 0.061 & 0.030 & 0.808 & 0.700 & 0.584 & 0.665 & 0.539 \\
\hline$P B$ & 0.088 & 0.030 & 0.698 & 0.717 & 0.535 & 0.559 & 0.576 \\
\hline$P E$ & 0.068 & 0.031 & 0.913 & 0.880 & 0.917 & 0.802 & 0.870 \\
\hline$P I$ & 0.065 & 0.032 & 0.481 & 0.573 & 0.514 & 0.337 & 0.434 \\
\hline$P R$ & 0.046 & 0.035 & 0.893 & 0.869 & 0.670 & 0.865 & 0.806 \\
\hline$R J$ & 0.050 & 0.022 & 0.921 & 0.822 & 0.935 & 0.846 & 0.797 \\
\hline$R N$ & 0.073 & 0.020 & 0.787 & 0.880 & 0.581 & 0.661 & 0.792 \\
\hline$R O$ & 0.086 & 0.043 & 0.795 & 0.759 & 0.777 & 0.704 & 0.745 \\
\hline$R R$ & 0.107 & 0.025 & 0.372 & 0.316 & 0.540 & 0.345 & 0.280 \\
\hline$R S$ & 0.054 & 0.036 & 0.878 & 0.740 & 0.624 & 0.865 & 0.692 \\
\hline$S C$ & 0.049 & 0.024 & 0.783 & 0.844 & 0.752 & 0.745 & 0.760 \\
\hline$S E$ & 0.080 & 0.031 & 0.661 & 0.829 & 0.679 & 0.575 & 0.831 \\
\hline$S P$ & 0.057 & 0.034 & 0.962 & 0.948 & 0.860 & 1.000 & 1.000 \\
\hline TO & 0.126 & 0.039 & 0.736 & 0.792 & 0.536 & 0.597 & 0.711 \\
\hline$B R$ & 0.052 & 0.027 & & & 0.836 & & \\
\hline
\end{tabular}

Notes: Descriptive statistics of state level consumption and income yearly data. $\rho$ denotes the correlation coefficient. The first and second columns report the standard deviation (sd) of consumption and income growth, respectively. Third and forth columns report the correlation of consumption and income growth with the aggregate level, respectively. The fifth column presents the correlation of income and consumption growth. Similarly, the last two columns report the correlation of consumption and income growth with São Paulo (reference region). Per capita Real Retail Sales was used as a consumption proxy, and per capita Real Gross State Product was used for income data. The sample period is from 2000 to 2017. Data source: IBGE.

Notice from Table 1 that the standard deviation of income and consumption is lower at the aggregate level for the majority of states. It is important to highlight that the consumption growth may present a higher standard deviation than the actual consumption data as we use retail sales data. According to Crucini and Hess $(2000)$, retail sales are more volatile than total consumption of durable and non durable goods.

A lower variance of income growth at the aggregate level suggests that there is scope for risk sharing within the country, while a smaller consumption growth variation suggests that risk sharing is not perfect among Brazilian states. Recall that in Arrow (1973) and Debreu's (1959) full risk sharing allocation each region consumes a fixed proportion of the aggregate income, which implies that its consumption growth rate should be the same. So, 
with risk sharing, the standard deviation of each state $\Delta c_{t}$ could diminish and get closer to the aggregate level, and the consumption growth correlations could get closer to 1 , reaching this value at a full risk sharing scenario.

We could notice from the third and sixth columns that while we have some states with a very high consumption synchrony with the aggregate level, others have a low correlation with national consumption, suggesting different degrees of risk sharing among the country and scope for the achievement of a higher integration.

\section{Country Level Data:}

For this case, Brazil was selected as the reference region as it is the biggest economy on the group. The following table reports the descriptive statistics for the country level data on the same manner as on the state level case.

Table 2: Descriptive statistics for MERCOSUL countries yearly per capita income and consumption data

\begin{tabular}{|c|c|c|c|c|c|c|c|}
\hline State & $\operatorname{sd}\left(\Delta c_{j t}\right)$ & $\mathbf{s d}\left(\Delta y_{j t}\right)$ & $\rho\left(\Delta c_{A G R t}, \Delta c_{j t}\right)$ & $\rho\left(\Delta y_{A G R t}, \Delta y_{j t}\right)$ & $\rho\left(\Delta y_{j t}, \Delta c_{j t}\right)$ & $\rho\left(\Delta c_{B R t}, \Delta c_{j t}\right)$ & $\rho\left(\Delta y_{B R t}, \Delta y_{j t}\right)$ \\
\hline Argentina & 0.058 & 0.053 & 0.477 & 0.554 & 0.923 & 0.136 & 0.286 \\
\hline Bolivia & 0.026 & 0.027 & 0.214 & 0.255 & 0.745 & 0.149 & 0.217 \\
\hline Brazil & 0.037 & 0.037 & 0.905 & 0.941 & 0.735 & 1.000 & 1.000 \\
\hline Chile & 0.057 & 0.046 & 0.135 & 0.192 & 0.831 & 0.015 & 0.055 \\
\hline Colombia & 0.023 & 0.020 & 0.530 & 0.624 & 0.800 & 0.411 & 0.520 \\
\hline Ecuador & 0.041 & 0.029 & 0.346 & 0.471 & 0.709 & 0.256 & 0.446 \\
\hline Paraguay & 0.032 & 0.034 & 0.159 & 0.438 & 0.634 & 0.077 & 0.378 \\
\hline Peru & 0.054 & 0.048 & 0.292 & 0.503 & 0.918 & 0.139 & 0.359 \\
\hline Uruguay & 0.052 & 0.042 & 0.301 & 0.467 & 0.879 & 0.091 & 0.295 \\
\hline Aggregate & 0.028 & 0.029 & & & 0.817 & & \\
\hline
\end{tabular}

Notes: Descriptive statistics of MERCOSUL countries consumption and income yearly data. $\rho$ denotes the correlation coefficient. The first and second columns report the standard deviation (sd) of consumption and income growth, respectively. Third and forth columns report the correlation of consumption and income growth with the aggregate level, respectively. The fifth column presents the correlation of income and consumption growth. Similarly, the last two columns report the correlation of consumption and income growth with Brazil (reference region). The data are on real and per capita terms. The sample period is from 1962 to 2018. Data source: IBGE.

From Table 2 we are able to notice that the volatility of per capita income growth is also smaller at the aggregate level for this data set, suggesting again the scope for risk sharing. The consumption growth volatility is also smaller at the aggregate level in comparison to most countries, and the nations with a higher volatility on consumption growth are also the ones with elevated fluctuation on income growths. A possible explanation for this is that shocks on domestic product are being translated into consumption, which is supported by the high correlation between income and consumption growths. Also, the low correlation 
among aggregate and individual consumption growths suggests a low degree of risk sharing between the South American countries.

\subsection{Methodology and Results}

This section is sub-divided into two sub-sections, one for each model from this chapter. On both of them the estimation methodology is described and the results presented.

\subsubsection{Crucini's (1999) model}

Recall that Crucini]s (1999) model estimable equation is given by:

$$
\Delta c_{j t}=\lambda_{j} \Delta c_{a t}+\left(1-\lambda_{j}\right) \Delta \hat{y p} p_{j t}+\epsilon_{j t}
$$

An important feature of this model is the presence of the term $\Delta y p_{j t}$ on the equation, which represents the update on permanent income forecast. In order to obtain $\Delta y p_{j t}, \operatorname{Crucini}(1999)$ assumes a specification for regional income growth. Following the author steps, equation (10) is estimated three times, each assuming a different process for income growth, in order to check the sensibility of the results to the process assumed to forecast regional income.

To understand how $\Delta \hat{y} p_{j t}$ is computed, recall that:

$$
\Delta \hat{y p} p_{j t}=(1-\beta) \sum_{k=0}^{\infty} \beta^{k}\left[\mathbb{E}_{t} y_{j t+k}-\mathbb{E}_{t-1} y_{j t+k}\right]
$$

So departing from an income process, we could calibrate a value for $\beta$ and compute the update on permanent income forecast based on the change of expectation of income path from $t-1$ to $t$. In order to calibrate $\beta$, we took average of annual real interest along the time of our analysis (2000-2017) and computed $\beta=\frac{1}{1+r}$, where $r$ represents the real interest rate. The value used for the interest rate was $6.6 \%$ per year, so the annual discount rate is given by $\beta=0,938$.

As in Crucinils (1999) paper, we assume three process for income growth:

$$
\begin{gathered}
\left(\begin{array}{c}
\Delta y_{a t} \\
\Delta y_{j t}
\end{array}\right)=\left(\begin{array}{cc}
A_{j}^{11} & A_{j}^{12} \\
A_{j}^{21} & A_{j}^{22}
\end{array}\right)\left(\begin{array}{c}
\Delta y_{a t-1} \\
\Delta y_{j t-1}
\end{array}\right)+\left(\begin{array}{c}
v_{a j t} \\
v_{j t}
\end{array}\right), \\
\Delta y_{j t}=\theta_{j} \Delta y_{j t-1}+v_{j t},
\end{gathered}
$$




$$
\Delta y_{j t}=v_{j t}
$$

To compute the estimated revision on permanent income for processes (13) and (14), consider an $\operatorname{ARMA}(\mathrm{p}, \mathrm{q})$ process for income:

$y_{t}=\rho_{1} y_{t-1}+\rho_{2} y_{t-2}+\rho_{2} y_{t-2}+\rho_{3} y_{t-3}+\ldots+\rho_{p} y_{t-p}+\epsilon_{t}+\phi_{1} \epsilon_{t-1}+\phi_{2} \epsilon_{t-2}+\phi_{3} \epsilon_{t-3}+\ldots+\phi_{q} \epsilon_{t-q}$

Flavin (1981) showed that the review on income forecast for an $\operatorname{ARMA}(\mathrm{p}, \mathrm{q})$ process is given by:

$$
\sum_{s=0}^{\infty} \beta\left(\mathbb{E}_{t} y_{t+s}-\mathbb{E}_{t-1} y_{t+s}\right)=\frac{1+\sum_{s=1}^{q} \beta^{s} \phi_{s}}{1-\sum_{j=1}^{p} \beta^{j} \rho_{j}} \epsilon_{t} .
$$

From equations (15) and (16), and with a value for $\beta$, we are able to compute $\Delta y p_{j t}$ for the processes denoted by equations (13) and (14), as they are special cases of a general ARMA process. The following sub-sections show in details how $\Delta y p_{j t}$ is computed for each income growth process assumed on this study.

\section{Case 1: Random Walk:}

The first specification assumed is a random walk for the income in level (or a white noise for income growth), given by the following equation in first difference:

$$
\Delta y_{j t}=\epsilon_{j t}
$$

Based on equations (14) and (15), we have that $\rho_{1}=1, \rho_{j}=0$ for all $j \neq 1$ and $\phi_{s}=0$ for all $s$. Using those values and equations (11) and (16), when income growth is a white noise process we have that $\Delta y p_{j t}=\epsilon_{j t}=\Delta y_{j t}$, then for this income specification the following equation is estimated:

$$
\Delta c_{j t}=\lambda_{j} \Delta c_{a t}+\left(1-\lambda_{j}\right) \Delta y_{j t}+\epsilon_{j t}
$$

Case 2: $\operatorname{AR}(1)$ : 
The second income specification assumed is given by:

$$
\Delta y_{j t}=\theta_{j} \Delta y_{j t-1}+\epsilon_{j t}
$$

Which represents an $\mathrm{AR}(1)$ process for income growth, and could be written as:

$$
y_{j t}=\left(1+\theta_{j}\right) y_{j t-1}-\theta_{j} y_{j t-2}+\epsilon_{j t} .
$$

So, according to equations (15) and (16) we have that $\rho_{1}=\left(1+\theta_{j}\right), \rho_{2}=\theta_{j}$ and $\rho_{j}=0$ for all $j \geq 2$ and $\phi_{s}=0$ for all $s$, thus the permanent income update for the $\operatorname{AR}(1)$ process is:

$$
\Delta y p_{j t}=\frac{(1-\beta) \epsilon_{t}}{1-\beta\left(1+\theta_{j}\right)+\beta^{2} \theta_{j}} .
$$

So we first estimate the equation (18), save the coefficient $\theta_{j}$ and the residuals to compute $\Delta y p_{j t}$, and then we proceed with the estimation of equation (10).

\section{Case 3: VAR(1):}

Now a joint process for individual and aggregate income growth is assumed, given by the system:

$$
\left(\begin{array}{c}
\Delta y_{a t} \\
\Delta y_{j t}
\end{array}\right)=\left(\begin{array}{cc}
A_{j}^{11} & A_{j}^{12} \\
A_{j}^{21} & A_{j}^{22}
\end{array}\right)\left(\begin{array}{c}
\Delta y_{a t-1} \\
\Delta y_{j t-1}
\end{array}\right)+\left(\begin{array}{c}
v_{a j t} \\
v_{j t}
\end{array}\right) .
$$

As we also have the aggregate income growth in the process, equation (16) is not helpful to estimate the revision on permanent income for this case. However, we have the following proposition, that is demonstrated on appendix B.

Proposition 1. When individual and permanent consumption growth follow a joint process given by the system (12), the update on the region $j$ permanent income will be given by $\Delta y p_{j t}=(1-\beta)\left(B_{j}^{21} v_{a j t}+B_{j}^{22} v_{j t}\right)$, in which $B^{i j}$ is defined as the ijth element of the matrix $\left(I-\beta \mathbf{A}_{j}\right)^{-1}$.

Proof. Demonstrated on Appendix B.

We have then that: 


$$
\mathbf{B}_{j}=\left(I-\beta \mathbf{A}_{j}\right)^{-1}=\left(\begin{array}{cc}
B_{j}^{11} & B_{j}^{12} \\
B_{j}^{21} & B_{j}^{22}
\end{array}\right)=\left(\begin{array}{cc}
\frac{1-\beta A_{j}^{22}}{\alpha} & \frac{\beta A_{j}^{12}}{\alpha} \\
\frac{\beta A_{j}^{21}}{\alpha} & \frac{1-\beta A_{j}^{11}}{\alpha}
\end{array}\right),
$$

in which $\alpha=\operatorname{Det}\left(I-\beta \mathbf{A}_{j}\right)$.

So $\Delta y p_{j t}=(1-\beta)\left(B_{j}^{21} v_{a j t}+B_{j}^{22} v_{j t}\right)$, with $B_{j}^{21}=\frac{\beta A_{j}^{21}}{\alpha}$ and $B_{j}^{22}=\frac{1-\beta A_{j}^{11}}{\alpha}$.

Notice that under this specification for income growth, regional income innovations are now important both directly as a source of income and indirectly as information about future aggregate income. This means that consumption growth will be positively correlated across regions because of risk sharing and because of their income dependence on aggregate shocks.

We proceed with the estimation of the $\operatorname{VAR}(1)$ model, save the residuals $v_{j t}$ and $v_{a j t}$ and use the estimated coefficients in order to calculate the multiplies $B_{j}^{21}$ and $B_{j}^{22}$, and then we calculate $\Delta y p_{j t}$, moving then to the estimation of (10).

\section{Estimation and Results}

On the last section it was pointed that equation (10) was being estimated assuming different measures of permanent income growth. To compute permanent income update, it is necessary to estimate equations for the assumed income process (equations 12-14), in order to save their residuals and coefficients.

As we have per state retail sales only from 2000 onward, we have only 17 observations per state, which could compromise the risk sharing equation estimation results. However, we do not need consumption data to estimate the $\operatorname{AR}(1)$ and $\operatorname{VAR}(1)$ process for income, so $\operatorname{AR}(1)$ and $\operatorname{VAR}(1)$ income processes are estimated withing the range of 1986-2017, and the residuals from 2000-2017 are saved to compute permanent income.

Before estimating (12) and (13), we proceed with an Augmented Dickey-Fuller unit root test for the log of income at both level and first difference. All the states presented stationarity at first difference while almost all presented non stationarity on level at $5 \%$ significance. The same was valid for Brazilian income data. The results of the ADF tests could be found on Tables 20 and 21 on Appendix D.

The following tables presents the values of $\operatorname{AR}(1)$ and $\operatorname{VAR}(1)$ income process estimations for both state and country level data. For the former case the average results across states is reported, while for the latter only the result for Brazil is shown on the table. The number of statistically significant coefficients at a $5 \%$ is also reported. The detailed results 
for all states and MERCOSUL countries could be found on appendix D.

Table 3: $\mathrm{AR}(1)$ income specification estimation results

\begin{tabular}{|c|c|c|c|c|}
\hline & $\theta_{j}$ & $\mathrm{sd}\left(\theta_{j}\right)$ & Multiplier & Number of Significant Coefficients \\
\cline { 1 - 5 } States & 0.249 & 0.175 & 1.367 & 9 \\
\cline { 1 - 2 } Brazil & 0.584 & 0.106 & 2.210 & - \\
\hline
\end{tabular}

Notes: Estimates of equation $\Delta y_{j t}=\theta_{j} \Delta y_{j, t-1}+v_{j t}$ for Brazilian states and aggregate income growth. The mean of the results for the table is reported on the table. The first and second columns presents $\theta_{j}$ estimation value and its standard deviation, respectively. The third column presents the multiplier for the computation of permanent income forecast update, while the last column reports the number of states with statistically significant coefficients at $5 \%$ significance level. Source: Self elaboration.

The estimates of the $\mathrm{AR}(1)$ process (equation 13) were significant at a level of $5 \%$ only for 9 of 27 states. This suggests that the random walk income growth specification may be the appropriate one for most states.

Table 4: VAR(1) income specification estimation results

\begin{tabular}{|c|c|c|c|c|c|c|}
\cline { 2 - 7 } \multicolumn{1}{c|}{} & \multicolumn{3}{c|}{$A^{21}$} & \multicolumn{3}{c|}{$A^{22}$} \\
\hline & coef & se & Significant Coefficients & coef & se & Significant Coefficients \\
\hline States & 0.367 & 0.313 & 5 & 0.031 & 0.239 & 3 \\
\hline Brazil & 0.407 & 0.220 & - & 0.191 & 0.241 & - \\
\hline
\end{tabular}

Notes: Estimation results of the regional equation on $\operatorname{VAR}(1)$ model of aggregate and regional income growth represented by equation (13). The results are reported for the state level estimates and for Brazil, which was estimated together with MERCOSUL states. The mean statistics are reported at the state level, along with the number of significant coefficients at $5 \%$ level. Source: Self elaboration.

At state level, the $\operatorname{VAR}(1)$ estimates significance is even worse, as the impact of lagged aggregate income on the regional growth is statistically different from zero for only 5 states, and the impact of lagged regional income is significant only on 3 states. This supports the idea that a RW is the best specification for regional income growth among the three (RW, AR and VAR). For the aggregate case, the coefficient on AR(1) estimation showed significance, however, both $A^{21}$ and $A^{22}$ are not significant on the $\operatorname{VAR}(1)$ estimation.

After obtaining the estimated coefficients from the income growth specifications, the permanent income forecast update is computed for each case as described on the previous section. We are able then to proceed with the estimation of the risk sharing equation (10).

During the development of Crucinils (1999) theoretical model, it was assumed that the aggregate consumption growth is the simple average of each state consumption growth, a consequence of the imposition that each state contributes to the pooling with the same 
fraction of their income. So, we proceed with the estimation of the model using the simple average across the states growth as $\Delta c_{a t}$.

We run a regression for equation (10) imposing the restriction that the coefficients sum to 1 , as is suggested by the theoretical mode 6 Then, the validity of the restriction is examined with the $\mathrm{F}$ test for the following hypothesis:

$$
\begin{aligned}
& H_{0}: \alpha_{1}+\alpha_{2}=1 \\
& H_{1}: \alpha_{1}+\alpha_{2} \neq 1,
\end{aligned}
$$

in which $\alpha_{1}$ and $\alpha_{2}$ are the coefficients related to $\Delta c_{a t}$ and $\Delta y_{j t}$ on equation (10), respectively. The F-statistic for the test is given by 7

$$
F=\frac{\left(S S E_{R}-S S E_{U}\right) / J}{S S E_{U} /(N-K)}
$$

in which $S S E$ is the sum of squares error, $J$ is the number of restrictions and $N-K$ is the number of degrees of freedom (observations - number of parameters estimated). The subscript $R$ indicates the restricted regression, while $U$ is the unrestricted.

From this point onward, the reporting of the results is divided on two sub-sections, one presenting the estimation results for the state level case, and the other for Brazil within MERCOSUL.

\section{State level estimates:}

Table 5 reports the results for equation (10) estimates for state level data using each assumption of the income growth process. The mean of the statistics are reported. The number of coefficients that are statistically equal to 0 and to 1 at a $5 \%$ level of significance is also reported. Finally, the last column of the tables reports the number of states in which the null hypothesis $H_{0}: \alpha_{1}+\alpha_{2}=1$ is not rejected, also at $5 \%$ significance ${ }^{8}$. The results of the estimation of equation (10) for each state could be found on appendix D.

\footnotetext{
${ }^{6}$ Recall that this restriction arises when we define permanent income to include risk sharing, even if it is not complete. Crucini (1999)

${ }^{7}$ Check Hill et al. (2018), chapter 6 .

${ }^{8}$ The critical values used for the $\mathrm{t}$ and $\mathrm{F}$ tests are $t(16)=2.119$ and $F(1,16)=4.494$
} 
Table 5: State level risk sharing coefficient estimates

\begin{tabular}{|c|ccc|cc|c|}
\hline Income & \multicolumn{3}{|c|}{ Mean Statistics } & \multicolumn{2}{|c|}{ t-Test } & \multirow{2}{*}{ F-Test } \\
\cline { 2 - 6 } Specification & $\lambda$ & $\mathbf{s e}(\lambda)$ & $R^{2}$ & $\lambda=0$ & $\lambda=1$ & \\
\hline RW & 0.885 & 0.218 & 0.689 & 0 & 20 & 4 \\
\hline AR(1) & 0.885 & 0.200 & 0.687 & 0 & 21 & 3 \\
\hline VAR(1) & 0.958 & 0.206 & 0.668 & 0 & 24 & 3 \\
\hline
\end{tabular}

Notes: Mean statistics from estimation of the equation $\Delta c_{j t}=\lambda_{j} \Delta c_{a t}+(1-$ $\left.\lambda_{j}\right) \Delta \hat{y p} p_{j t}+\epsilon_{j t}$ per state. The last three columns of the table present the number of coefficients statistically equal to 0 , to 1 and the number of states in which the restriction imposed on the regression coefficients is not valid, respectively. Source: Self elaboration.

The mean of the results for RW and AR(1) were very similar, pointing to a risk sharing degree of 0.885 , while for $\operatorname{VAR}(1)$ the mean value is 0.958 . Notice that they presented certain sensibility to the income specification adopted in comparison to the VAR(1) case. However, on all cases a considerable amount of the states presented estimates statistically equal to 1 and only a few cases rejected the hypothesis that the coefficients on average consumption growth and the innovation to regional permanent income sum to unity. According to Crucini (1999), not rejecting this null hypothesis suggests the value of defining permanent income such that it includes risk-sharing behavior, even when risk sharing is incomplete.

It worth highlighting that the size of the database may be a problem, as there are only 17 observations per state. In light of this, we also estimate equation (10) as a panel. The results are reported on Tables 6 .

Table 6: Equation (10) panel OLS estimates

\begin{tabular}{|c|c|c|c|c|c|c|}
\hline & $\lambda$ & sd $(\lambda)$ & $\begin{array}{c}\text { t-statistic } \\
(\lambda=0)\end{array}$ & $\begin{array}{c}\text { t-statistic } \\
(\lambda=1)\end{array}$ & $R^{2}$ & $\begin{array}{c}\text { F-test } \\
(\text { P-Value })\end{array}$ \\
\hline RW & 0.859 & 0.042 & 17.394 & -3.370 & 0.642 & 0.000 \\
AR1 & 0.854 & 0.037 & 22.045 & -3.922 & 0.637 & 0.000 \\
VAR1 & 0.943 & 0.039 & 13.298 & -1.437 & 0.622 & 0.004 \\
\hline
\end{tabular}

Notes: Panel OLS estimation of equation $\Delta c_{j t}=\lambda_{j} \Delta c_{a t}+\left(1-\lambda_{j}\right) \Delta \hat{y p}_{j t}+\epsilon_{j t}$ for Brazilian state level data. The results are reported for each income growth specification assumed in order to compute permanent income update. The first and second columns report the estimated value for $\lambda$ and its standard deviation, respectively. The third and fourth columns report the t-statistics to test if $\lambda=0$ and $\lambda=1$, respectively. The fifth column presents the $R^{2}$ of the regressions, while the last reports the F-test statistic for the restriction that the regression coefficients sum to 1. Source: Self Elaboration.

The results for the panel regressions are lower then the average of the per state results, however they are not much different. The key point here is that for RW and AR(1) cases, they are not statistically equal to 1 . The null hypothesis that the coefficients on average 
consumption growth and on the innovation to regional permanent income sum to unity is not rejected on any case at 5\% significance. Recall that the income specification estimates and unit root tests suggested that the regional income growth follows approximately a random walk for most states, so it is reasonable to expect that the estimates of risk sharing assuming this specification are more trustworthy.

The estimations point then that there is a high synchronicity among Brazilian states consumption, as a degree of risk sharing of around 0.86 is estimated if we assume the random walk specification is the most adequate. However, there is no evidence of complete risk sharing among the states.

\section{Aggregate level estimates:}

Table 7 reports the results of equation (10) estimation for Brazilian risk sharing with MERCOSUL countries. Table is organized as the previous one.

Table 7: Brazil degree of risk sharing within MERCOSUL estimates

\begin{tabular}{|c|c|c|c|c|c|c|}
\hline Specification & $\lambda$ & $\mathbf{s d}(\lambda)$ & t-statistic $(\lambda=0)$ & t-statistic $(\lambda=1)$ & $R^{2}$ & F-test \\
\cline { 1 - 4 } RW & 0.269 & 0.097 & 2.762 & -7.522 & 0.525 & 0.854 \\
\cline { 1 - 1 } & 0.425 & 0.058 & 7.325 & -9.916 & 0.392 & 1.676 \\
\cline { 1 - 3 } & 0.649 & 0.019 & 34.585 & -18.670 & 0.321 & 9.980 \\
\hline
\end{tabular}

Notes: OLS estimation of equation $\Delta c_{j t}=\lambda_{j} \Delta c_{a t}+\left(1-\lambda_{j}\right) \Delta \hat{y p} p_{j t}+\epsilon_{j t}$ for Brazil. The aggregate consumption and income considers the data of MERCOSUL countries. The first and second columns report the estimated value for $\lambda$ and its standard deviation, respectively. The third and fourth columns report the t-statistics to test if $\lambda=0$ and $\lambda=1$, respectively. The fifth column presents the $R^{2}$ of the regressions, while the last reports the F-test statistic for the restriction that the regression coefficients sum to 1 Source: Self elaboration.

Notice that at the aggregate level the results differs on two aspects. First, the degree of risk sharing estimated is much lower and statistically different from one, with strong evidence against complete risk sharing $(\lambda=1)$. Second, the results showed a higher sensibility to the assumed income process. This may be related to the fact that the income on aggregate level was predicted with more precision in comparison to states. Despite the higher variability of the results in response to the income growth process assumed, they suggest that the degree of risk sharing is lower at the international case in comparison to the regional. 


\subsubsection{Asdrubali and Kim's (2008) model}

Recall from section 2.1.2 that the main model equation of Asdrubali and Kim $\mathrm{s}$ (2008) is given by:

$$
\Delta c_{j t}=\mu_{j}+\lambda_{j} \Delta c_{a t}+\left(1-\gamma_{j}\right)\left(1-\lambda_{j}\right) \Delta y_{j t}+\eta_{j t}
$$

in which

$$
\eta_{j t} \equiv \gamma_{j}\left(\bar{\epsilon}_{j t}-\lambda_{j} \epsilon_{j t}\right)
$$

and

$$
\epsilon_{j t}=(1-\beta) \sum_{k=0}^{\infty} \beta^{k}\left[\mathbb{E}_{t} y_{j t+k}-\mathbb{E}_{t-1} y_{j t+k}\right],
$$

resulting on the following estimate relation:

$$
\Delta c_{j t}=\mu_{j}+\lambda_{j} \Delta c_{a t}+\left(1-\gamma_{j}\right)\left(1-\lambda_{j}\right) \Delta y_{j t}+\mu_{j t},
$$

where $\mu_{j t}$ is an independent identically distributed error term.

We work with the case on which intertemporal consumption smoothing is not perfect, so we have that $0<\gamma<1$. For all the cases on which $\gamma \neq 0$, the revision on permanent income is omitted to $\mu_{j t}$, resulting on biased Ordinary Least Square (OLS) estimations, because $\eta_{j t}$ is not observed and could not be orthogonal to $\Delta c_{a t}$ and $\Delta y_{j t}$. A solution to this problem is the use of Instrumental Variables (IV) estimation.

Accordingly to Wooldridge (2015), the IV analysis requires instruments to isolate the movements of the endogenous variables that are correlated with $\mu_{j t}$. An instrument $(Z)$ must satisfy two conditions concerning an endogenous variable $(X): \operatorname{corr}(X, Z) \neq 0$ (instrument relevance) and $\operatorname{corr}(\mu, Z)=0$ (instrument exogeneity). If an instrument is relevant and exogenous, it is considered a valid instrument. It is also desirable that $\mathrm{Z}$ explains a large proportion of the variation o $\mathrm{X}$, otherwise it will be considered a weak instrument, which can bias the estimates and cause size distortions on hypothesis tests.

The IV procedure requires that the number of instruments is at least the number of endogenous regressors on the problem, so for Asdrubali and Kim s (2008) model we need a minimum of two instruments. Following the authors strategy, we used the lagged values of $\Delta c_{j}, \Delta c_{a}, \Delta y_{j}$ and $\Delta y_{a}$ as instruments, as the lagged values are good predictors of income 
and consumption and thier process might be cointegrated. Additionally, the lagged values are not correlated with the updates on the forecast of permanent income, as it only varies upon new information.

The equations were estimated for each state, but for most of the cases the results assumed unreliable values and the majority of them were not statistically significant which could be a consequence of the small size of the database, as we have only 14 observations when we use lagged values as instruments, so we proceed with a panel estimation approach.

The estimations are repeated two times, each with a different group of instruments. First we use one lag of $\Delta c_{j}, \Delta c_{a}, \Delta y_{j}$ and $\Delta y_{a}$ as instruments, and on the second estimation we used 1 and 2 lags of the mentioned variables. For comparison purposes, we further report the results for OLS estimation..

We also proceed with three tests for the instrumental variables estimation: weak instruments, Wu-Hausman and Sargan. The weak instruments test checks the strength of the correlation of the instruments with the endogenous explanatory variable. It performs an F-test on the first-stage regression of the IV procedure. Wu-Hausman tests the consistency of the IV estimator in comparison to the OLS. It the null of the test is rejected, using the OLS estimator is preferable. Finally, the Sargan tests overidentification restrictions. This test is used when the number of instruments is bigger then the regressors. It could be interpreted as a test for the validity of the instruments, as it tests if all exogenous instruments are in fact exogenous, and uncorrelated with the model residuals.

Table 8 reports the results of the estimation of equation (21) at state level data. Besides reporting the estimated values and their standard deviations (on brackets), the table also presents the values for $\mathrm{t}$ statistics to test if the coefficients are statistically equal to 0 and to 1 . In sequence, Table 9 reports the statistics and P-values for the tests mentioned on the last paragraph.

Table 8: IV panel estimation results of equation (21)

\begin{tabular}{|c|c|c|c|c|c|c|c|}
\hline Instruments (lags)/Method & $\lambda$ & $\mathrm{t}=\mathbf{0}$ & $t=1$ & $(1-\gamma)(1-\lambda)$ & $\mathbf{t}=\mathbf{0}$ & $\mathbf{t}=1$ & $R^{2}$ \\
\hline ( & $\begin{array}{c}0.921 \\
(0.150)\end{array}$ & 6.139 & -0.523 & $\begin{array}{c}0.269 \\
(0.462)\end{array}$ & 0.582 & -1.585 & 0.635 \\
\hline $1-2$ & $\begin{array}{c}0.957 \\
(0.148)\end{array}$ & 6.484 & -0.292 & $\begin{array}{c}0.155 \\
(0.461)\end{array}$ & 0.336 & -1.833 & 0.626 \\
\hline$O L S$ & $\begin{array}{c}0.829 \\
(0.046)\end{array}$ & 18.028 & -3.729 & $\begin{array}{c}0.497 \\
(0.079)\end{array}$ & 6.302 & -6.365 & 0.642 \\
\hline
\end{tabular}

Notes: Instrumental Variables estimation results of equation (21) for each number of instruments adopted. Source: Self elaboration. 
Table 9: Diagnostic tests of equation (21) panel IV estimation

\begin{tabular}{|c|cc|cc|}
\hline \multirow{2}{*}{ Test/Instruments (lags) } & \multicolumn{2}{|c|}{$\mathbf{1}$} & \multicolumn{2}{c|}{ 1-2 } \\
\cline { 2 - 5 } & Statistic & P-Value & Statistic & P-Value \\
\hline Weak Instruments $\left(\Delta c_{a t}\right)$ & 42.398 & 0.000 & 32.091 & 0.000 \\
Weak Instruments $\left(\Delta y_{j t}\right)$ & 10.390 & 0.000 & 7.376 & 0.000 \\
\hline Wu-Hausman & 0.238 & 0.788 & 0.462 & 0.630 \\
\hline Sargan & 14.143 & 0.001 & 16.389 & 0.003 \\
\hline
\end{tabular}

Notes: Results for Weak Instruments, Wu-Hausman and Sargan tests for the estimation of equation (21). Source: Self elaboration.

Notice from the Wu-Hausman test P-Value for both cases that the estimation using instruments is not consistent, suggesting that the OLS estimator is preferable. Weak instruments, Wu-Hausman and Sargan tests seems to be ok for all other cases. The instrumental variables estimations pointed to 0.921 and 0.957 , which are statistically equal to one at $5 \%$ significance. The OLS result is 0.829 , but is different from 1 at $5 \%$ significance. Notice however, that the IV estimates are more volatile, and Wu-Hausman test pointed to a preference to OLS estimation. Those results are in line with the findings from the previous section. Notice that the OLS estimated equation is not the same as from the previous model, as we do not apply any restriction on the coefficients.

Table 10 presents the results for the aggregate level, while Table 11 contains the diagnostic tests.

Table 10: IV panel estimation results of equation (21) (Brazil)

\begin{tabular}{|c|c|c|c|c|c|c|c|}
\hline Instruments (lags)/Method & $\lambda$ & $\mathbf{t}=\mathbf{0}$ & $t=1$ & $(1-\gamma)(1-\lambda)$ & $\mathbf{t}=\mathbf{0}$ & $t=1$ & R2 \\
\hline ( & $\begin{array}{c}0.200 \\
(0.377)\end{array}$ & 0.531 & -2.120 & $\begin{array}{c}0.465 \\
(0.254)\end{array}$ & 1.833 & -2.108 & 0.493 \\
\hline $1-2$ & $\begin{array}{c}0.054 \\
(0.325)\end{array}$ & 0.167 & -2.910 & $\begin{array}{c}0.553 \\
(0.206)\end{array}$ & 2.682 & -2.171 & 0.510 \\
\hline$O L S$ & $\begin{array}{c}0.104 \\
(0.170)\end{array}$ & 0.610 & -5.271 & $\begin{array}{c}0.694 \\
(0.108)\end{array}$ & 6.405 & -2.827 & 0.536 \\
\hline
\end{tabular}

Notes: Instrumental Variables estimation results of equation (21) for each number of instruments adopted. Source: Self elaboration. 
Table 11: Diagnostic tests of equation (21) panel IV estimation (Brazil)

\begin{tabular}{|c|cc|cc|}
\hline \multirow{2}{*}{ Test/Instruments (lags) } & \multicolumn{2}{|c|}{$\mathbf{1}$} & \multicolumn{2}{c|}{ 1-2 } \\
\cline { 2 - 5 } & Statistic & P-Value & Statistic & P-Value \\
\hline Weak Instruments $\left(\Delta c_{a t}\right)$ & 6.431 & 0.001 & 2.484 & 0.025 \\
Weak Instruments $\left(\Delta y_{j t}\right)$ & 5.549 & 0.002 & 2.519 & 0.024 \\
\hline Wu-Hausman & 0.683 & 0.510 & 0.631 & 0.536 \\
\hline Sargan & 0.443 & 0.506 & 6.472 & 0.372 \\
\hline
\end{tabular}

Notes: Results for Weak Instruments, Wu-Hausman and Sargan tests for the estimation of equation (21). Source: Self elaboration.

The Weak Instruments tests were not rejected for both 1 and 1-2 lags IV estimations. However, both Sargan and Wu-Hausman tests were rejected, suggesting again that the OLS estimator is preferable. At odds with the results from Crucini $s(1999)$ model, a low degree of risk sharing was estimated, and for all procedures the coefficients are statistically equal to zero.

Comparing the results from both sections for the country case, there is not much conclusive evidence of what is the degree of risk sharing of the country with the MERCOSUL neighbors. However, both Asdrubali and Kim (2008) and Crucini (1999) models suggest that the degree of regional risk sharing is higher than the international for the Brazilian case. 


\section{The Role of Fiscal Federalism on Brazilian Risk Sharing}

The results from the least chapter pointed to a high degree of integration among the Brazilian states. As the government has the power to move funds across states, it is expected that its tax-transfer system is responsible for some part of the smoothing of regional shocks within the country. The results on empirical literature suggests that fiscal federal flows are responsible for a considerable amount of risk sharing on developed countries. Athanasoulis and Wincoop (2001) find that the tax-transfers system are responsible for around $14 \%$ of risk sharing within USA states, while Sala-i Martin and Sachs (1991) find this value is between $33 \%$ to $40 \%$, and Asdrubali et al. (1996) result points to a value of $13 \%$ also for United States.

This chapter investigates the role of fiscal federalism on soothing the effects of regional shocks on private consumption. This chapter is organized as follows. The first section brings a discussion of the main theoretical arguments in favor and against fiscal centralization in context of risk sharing and stabilization. The second section discusses the models used to proceed with the empirical analysis, while the third section presents the data used on the estimations, bringing a detailed discussion of taxes and transfers data for brazilian regional case. Finally, the last section covers the empirical methodology and the results.

\subsection{Fiscal Centralization as a Source of Risk Sharing}

As discussed on the previous chapter, it is desirable to reduce the volatility on regional consumption, which could be done in order to leave regions exposed only to aggregate shocks. This volatility reduction leads to welfare gains, and it could be achieved solely by capital and financial markets, if they are complete. However, it is reasonable to expect that those markets are not perfect, as they are not very well developed in all countries and some agents do not have access to it.

The necessity of a fiscal mechanism on risk sharing is clearer then when we argue that financial and capital markets are not complete, so regions are not able to hold portfolios that protect them from individual shocks. There is a broad discussion on the literature regarding the role and advantages of fiscal centralization on risk sharing and as a stabilizer.

Another reason that supports fiscal centralization, as pointed on Poghosyan et al. (2016), is that the regions develop better under a stable economy, which is a positive externality for all the regions over time. For example, the stabilization effects could leak to other states through interstate trade spillovers. 
It is also possible for regional governments to engage on countercyclical deficits to achieve income stabilization. However, budget deficits have to be repaid in the future, so the regional governments could not be able to sustain the extra expanses for a long time. In a context of Ricardian agents 9 the stabilization provided by a local government could be hampered, as agents may expect higher taxes in the future to pay for the rising expanses and decide to save money on the short term. When the stabilization policy is provided by a central government, the Ricardian equivalence may not hold, because funds from other regions could be used to balance the regional deficit. Sala-i Martin and Sachs (1991)

Regional governments could also avoid running large deficits because they fear that workers and firms may leave the region. This happens in a context of mobile factors of production, because tax raises are expected after large deficits, and factors of production tend to remain in the state while taxes are low and leave when they increase. This effect reduces the potential role for income smoothing regional deficits. Sala-i Martin and Sachs $(1991$

A subject that is closely related to fiscal policy and risk sharing is optimal currency areas, first presented by Mundell (1961), which discussed the appropriate size and properties of a region to adopt the same currency. This discussion came up with the debates about the creation of the European Monetary Union and the adoption of a single currency.

The key point here lies on the role of exchange rates as an adjustment mechanism. An imbalance among regions caused by an idiosyncratic shock could be restored by changes on terms of trade, or in other words, movements on real exchange rates. Inside a currency area, the nominal exchange rate is fixed, so in case of non mobile factors of production, equilibrium is only restored if you have unemployment on the region that suffered the negative shock or inflation on the other regions. If prices are sticky on the short run, equilibrium could take longer to be restored. So capital and labor mobility are important factors on the determination of an optimal currency area, as the nominal exchange rate is unable to move and fix regional imbalances.

So, a large federation that uses the same currency may have a slow adjustment to regional shocks, as it is subjected to a fixed nominal exchange rate and prices could be sticky on the short run and capital and labor can have limited mobility. This justifies room for fiscal transfers to offset idiosyncratic shocks on large federations, which could restore equilibrium

\footnotetext{
${ }^{9}$ Ricardian agents are assumed to be optimizes, rational expectation agents, as they save when government raises its expanses because they anticipate the government will raise tax rates in the future in order to pay for the deficits and respect its intertemporal budget constraint.
} 
by taxing the prosperous region and transferring the funds to the region in distress.

The optimal amount of risk sharing provided by the central government is opened to debate. Despite the arguments supporting a fiscal union providing risk sharing, there are also drawbacks pointed on the literature regarding this subject. A first issue, presented on Persson and Tabellini (1996), is how to design an optimal tax system in context of heterogeneous agents. As regions have different income and risk structures, there are interest conflicts on determining the design and size of intraregional risk sharing provided by the tax and transfer system, which is usually different than optimal.

A second issue regarding intraregional risk sharing insurance is a moral hazard problem that emerges in this context. With risk sharing insurance, regional governments have less incentives to invest on risk-avoidance policies, so a regional income volatility that is expected to reduce over time could remain at the same level or even get worse. Another moral hazard problem is that the distorting effect of taxes and transfers could affect the market mechanisms of adjustment to idiosyncratic shocks von Hagen (2000)

Before discussing the empirical models we use on this chapter, it is important to highlight that a practical difficulty to estimate the risk sharing effect of fiscal taxes and transfers is the redistributive aspect of this mechanism, which seeks to reduce regional inequalities among a country and the existence is very clear on the Brazilian case, as some states are consistently net payers of funds while other are receivers. So isolating those welfare effects is a issue that we should keep in mind on proceeding with the estimations.

\subsection{Theoretical Framework}

Our goal is to estimate how federal taxes and transfers respond to income shocks and affect its volatility. For that we rely on two different approaches that the available data for Brazil allows. The first one estimates the value of taxes and transfers directly against economic performance, as in Sala-i Martin and Sachs (1991), while the second uses a gross state product variance decomposition as in Asdrubali et al. (1996).

\subsubsection{Sala-i Martin and Sachs's (1991) Approach}

We depart from the following equation:

$$
\Delta Y D_{j t}=\Delta Y_{j t}+\Delta T R_{j t}-\Delta T X_{j t}
$$


in which $\mathrm{Y}$ is GDP, TR are the federal transfers, TX federal taxes and YD is disposable income. The index $j$ denotes the region and $t$ is a time subscript.

Define then $\beta_{T X}$ and $\beta_{T R}$ as the elasticities of taxes and transfers, respectively, in relation to variations in income. They are given by the following equations (notice the subscripts are suppressed):

$$
\beta_{T X}=\frac{\frac{\Delta T X}{T X}}{\frac{\Delta Y}{Y}},
$$

and

$$
\beta_{T R}=\frac{\frac{\Delta T R}{T R}}{\frac{\Delta Y}{Y}} .
$$

Using equations (23) and (24), (22) can be rewritten as:

$$
\Delta Y D=\Delta Y\left(1-\beta_{T X} \frac{T X}{Y}+\beta_{T R} \frac{T R}{Y}\right)
$$

and defining:

$$
\lambda=1-\beta_{T X} \frac{T X}{Y}+\beta_{T R} \frac{T R}{Y}
$$

we have:

$$
\Delta Y D=\Delta Y * \lambda
$$

Notice then that $\lambda$ could be interpreted as the effect of net fiscal transfers on the regional disposable income. We expect $\beta_{T X}>0$ and $\beta_{T R}<0$, as pro-cyclical taxes and countercyclical transfers stabilize disposable income in face of regional shocks. The values of $\beta_{T X}>0$ and $\beta_{T R}<0$ could be found by estimation of the following equations:

$$
\ln \left(T X_{i t}\right)=\alpha_{T X}+\beta_{T X} \ln \left(Y_{i t}\right)+\gamma_{T X} \text { Trend }+\mu_{i t},
$$

and

$$
\ln \left(T R_{i t}\right)=\alpha_{T R}+\beta_{T R} \ln \left(Y_{i t}\right)+\gamma_{T R} \text { Trend }+\epsilon_{i t},
$$

in which TX refers to real tax revenue per capita, $\mathrm{Y}$ is real income per capita and TR is real value of transfers per capita. The trend component reflects upward/downward trends in 
relative taxes that are not explained by the relative variations in income.

Sala-i Martin and Sachs (1991) mention some important issues concerning the empirical implementation of equations (27) and (28). They account for the possibility that the federal government could absorb the effects of recessions running deficits. So to make sure the federal deficits effects are not driving the results, they estimate the equations using the data of each region relative to the aggregate level, as given by the equations below:

$$
\ln \left(\frac{T X_{i t}}{T X_{t}}\right)=\alpha_{T X}+\beta_{T X} \ln \left(\frac{Y_{i t}}{Y_{t}}\right)+\gamma_{T X} \text { Trend }+\mu_{i t}
$$

and

$$
\ln \left(\frac{T R_{i t}}{T R_{t}}\right)=\alpha_{T R}+\beta_{T R} \ln \left(\frac{Y_{i t}}{Y_{t}}\right)+\gamma_{T R} \text { Trend }+\epsilon_{i t},
$$

in which the variables without the subindex $i$ represents the aggregate level (on per capita terms).

Another problem pointed by Sala-i Martin and Sachs (1991) is the presence of simultaneity bias on the equations. As higher taxes may depress economic activity, the estimates of equation (29) could present a negative bias. A similar argument is valid for transfers, as higher transfers could enhance economic activity, which will bias the parameter estimate towards zero. With those problems in mind, the authors suggest an instrumental variables procedure for the estimation.

An additional problem highlighted by Sala-i Martin and Sachs (1991) is that the error terms from equations (29) and (30) may be heteroscedastic, and they can also be correlated across regions, so the authors also estimate all the regions at the same time in a seemingly unrelated regression estimation system (SUR).

\subsubsection{Asdrubali et al.'s (1996) Variance Decomposition Approach}

In this section, we present the methodology used by Asdrubali et al. (1996), which is able to quantify the role of each risk sharing channel on income smoothing via a variance decomposition procedure. As the data available for Brazil do not allow us to account income after the action of each existent risk sharing channel, we adapt the methodology in a way that enables us to account for the role of tax and transfers on risk sharing. 
We start with the following identity 10

$$
g s p_{i}=\frac{g s p_{i}}{d s i_{i}} \frac{d s i_{i}}{c_{i}} c_{i}
$$

in which $g s p_{i}$ represents the gross state product of region $i, d s i_{i}$ represents the disposable state income, which consists on $g s p_{i}$ minus taxes plus transfers sent to region $i$ and $c_{i}$ denotes region $i$ consumption level.

Taking logs of (31) we have:

$$
\log \left(g s p_{i}\right)=\log \left(g s p_{i}\right)-\log \left(d s i_{i}\right)+\log \left(d s p_{i}\right)-\log \left(c_{i}\right)+\log \left(c_{i}\right)
$$

then we take first difference:

$$
\Delta \log \left(g s p_{i}\right)=\Delta \log \left(g s p_{i}\right)-\Delta \log \left(d s i_{i}\right)+\Delta \log \left(d s p_{i}\right)-\Delta \log \left(c_{i}\right)+\Delta \log \left(c_{i}\right),
$$

and multiplying the equation above by $\Delta \log \left(g s p_{i}\right)$ :

$$
\begin{aligned}
{\left[\Delta \log \left(g s p_{i}\right)\right]^{2}=} & {\left[\Delta \log \left(g s p_{i}\right)-\Delta \log \left(d s i_{i}\right)\right] \Delta \log \left(g s p_{i}\right) } \\
& +\left[\Delta \log \left(d s p_{i}\right)-\Delta \log \left(c_{i}\right)\right] \Delta \log \left(g s p_{i}\right)+\left[\Delta \log \left(c_{i}\right)\right] \Delta \log \left(g s p_{i}\right),
\end{aligned}
$$

and finally, taking expectations of the equation above 11 , we have:

$$
\begin{aligned}
\operatorname{Var}\left(\Delta \log \left(g s p_{i}\right)\right)= & \operatorname{Cov}\left(\Delta \log \left(g s p_{i}\right), \Delta \log \left(g s p_{i}\right)-\Delta \log \left(d s i_{i}\right)\right) \\
& +\operatorname{Cov}\left(\Delta \log \left(g s p_{i}\right), \Delta \log \left(d s p_{i}\right)-\Delta \log \left(c_{i}\right)\right)+\operatorname{Cov}\left(\Delta \log \left(g s p_{i}\right), \Delta \log \left(c_{i}\right)\right) .
\end{aligned}
$$

Equation (33) gives a good intuition of how Asdrubali et al. s (1996) methodology works. If the tax-transfer system achieves full risk sharing, $d s i$ should not move with $g s p$, as tax and transfer will compensate the region for any favorable or adverse shock. If complete smoothing is achieved after the other risk sharing channels then $g s p$ should not move with $c$. Additionally, if smoothing takes place via the tax-transfer system and via the other channels we have that $g s p$ varies positively with $\frac{g s p}{d s i}$ and with $\frac{d s i}{c}$. This means that the absolute value of $\Delta g s p$ should by higher than $\Delta d s i$, which should exceed $\Delta c$.

We divide then equation (33) by $\operatorname{Var}\left(\Delta \log \left(g s p_{i}\right)\right)$, leaving us:

$$
1=\beta_{F}+\beta_{C}+\beta_{\mu},
$$

\footnotetext{
${ }^{10}$ Notice the time index is suppressed.

${ }^{11}$ Notice we assume that $\mathbb{E}\left(\Delta \log \left(g s p_{i}\right)\right)=0$
} 
in which

$$
\begin{gathered}
\beta_{F}=\frac{\operatorname{Cov}\left(\Delta \log \left(g s p_{i}\right), \Delta \log \left(g s p_{i}\right)-\Delta \log \left(d s i_{i}\right)\right)}{\operatorname{Var}\left(\Delta \log \left(g s p_{i}\right)\right)}, \\
\beta_{C}=\frac{\operatorname{Cov}\left(\Delta \log \left(g s p_{i}\right), \Delta \log \left(d s i_{i}\right)-\Delta \log \left(c_{i}\right)\right)}{\operatorname{Var}\left(\Delta \log \left(g s p_{i}\right)\right)}, \\
\beta_{\mu}=\frac{\operatorname{Cov}\left(\Delta \log \left(g s p_{i}\right), \Delta \log \left(c_{i}\right)\right)}{\operatorname{Var}\left(\Delta \log \left(g s p_{i}\right)\right)} .
\end{gathered}
$$

So equation (34) is a decomposition of total risk sharing, with $\beta_{F}$ referring to the tax-transfer system, $\beta_{C}$ to other channels and $\beta_{\mu}$ to the non smoothed part of income. Notice that $\beta_{F}+\beta_{C}$ represents the percentage of income shocks that are smoothed. If we have full risk sharing, then $\operatorname{Cov}\left(\Delta \log \left(g s p_{i}\right), \Delta \log \left(c_{i}\right)\right)$, and $\beta_{\mu}$ should equal zero. $\beta_{F}, \beta_{C}$ and $\beta_{\mu}$ could be found running the following regressions:

$$
\begin{gathered}
\Delta \log \left(g s p_{i t}\right)-\Delta \log \left(d s i_{i t}\right)=v_{F, t}+\beta_{F} \Delta \log \left(g s p_{i t}\right)+\epsilon_{F, i t}, \\
\Delta \log \left(d s i_{i t}\right)-\Delta \log \left(c_{i t}\right)=v_{C, t}+\beta_{C} \Delta \log \left(g s p_{i t}\right)+\epsilon_{C, i t}, \\
\Delta \log \left(c_{i t}\right)=v_{\mu, t}+\beta_{\mu} \Delta \log \left(g s p_{i t}\right)+\epsilon_{\mu, i t}
\end{gathered}
$$

in which $v$ represents a time fixed effect and $\epsilon$ is the error term. Accordingly to Sørensen and Yosha (1998), in the presence of time fixed effects the $\beta^{\prime} s$ from the equations are weighted averages of the year by year cross-sectional regressions. They also capture effects of growth on aggregate output.

\subsection{Brazilian Taxes and Transfers Data}

This section presents some details of the database and descriptive statistics about the taxes and transfers data used to estimate the models from this chapter. More details of the data could be found on the appendix C.

It is possible to note from the development of the models on section 3.2 that per capita income and consumption data at state level are used on the estimations. This part of the database is the same as from the previous chapter. Additionally, we use data federal 
taxes and transfers.

The state level taxation data was collected from Brazilian Federal Revenue. This data is available on a monthly frequency, and ranges from 2001.01 to 2019.12 . To construct the total transfer to each state, two different databases were aggregated, as transfers are done both to state and city level governments. We aggregate the city transfers by each state and summed with transfers direct to the state level government in order to construct this variable. This data was collected from Brazilian National Treasury. Is is available at a monthly frequency and ranges from 1997.01 to 2019.12.

As we work with both taxes and transfers at a yearly frequency, this data was aggregated over the year. In order to find the per capita and real values, the population and state price indexes data described on the last chapter were used. The reminder of this section brings some analysis of the taxes and transfers data to Brazilian states in order to explore the characteristics of the fiscal system on the country.

The union transfers in Brazil are classified in two different groups: constitutional and discretionary transfers. The first group consists on the transfers arising from legal imposition, while the second are not determined by the constitution. The discretionary transfers are much rarer and smaller in volume than the constitutional transfers. The redistributive role of Brazilian fiscal system is evident from the data, as some states consistently receive less funds than they pay while other could be found in the opposite situation. The figures above exhibits the real net transfers for each state on 2002 and 2019. 
Figure 1: Real net transfers per Brazilian state on 2002

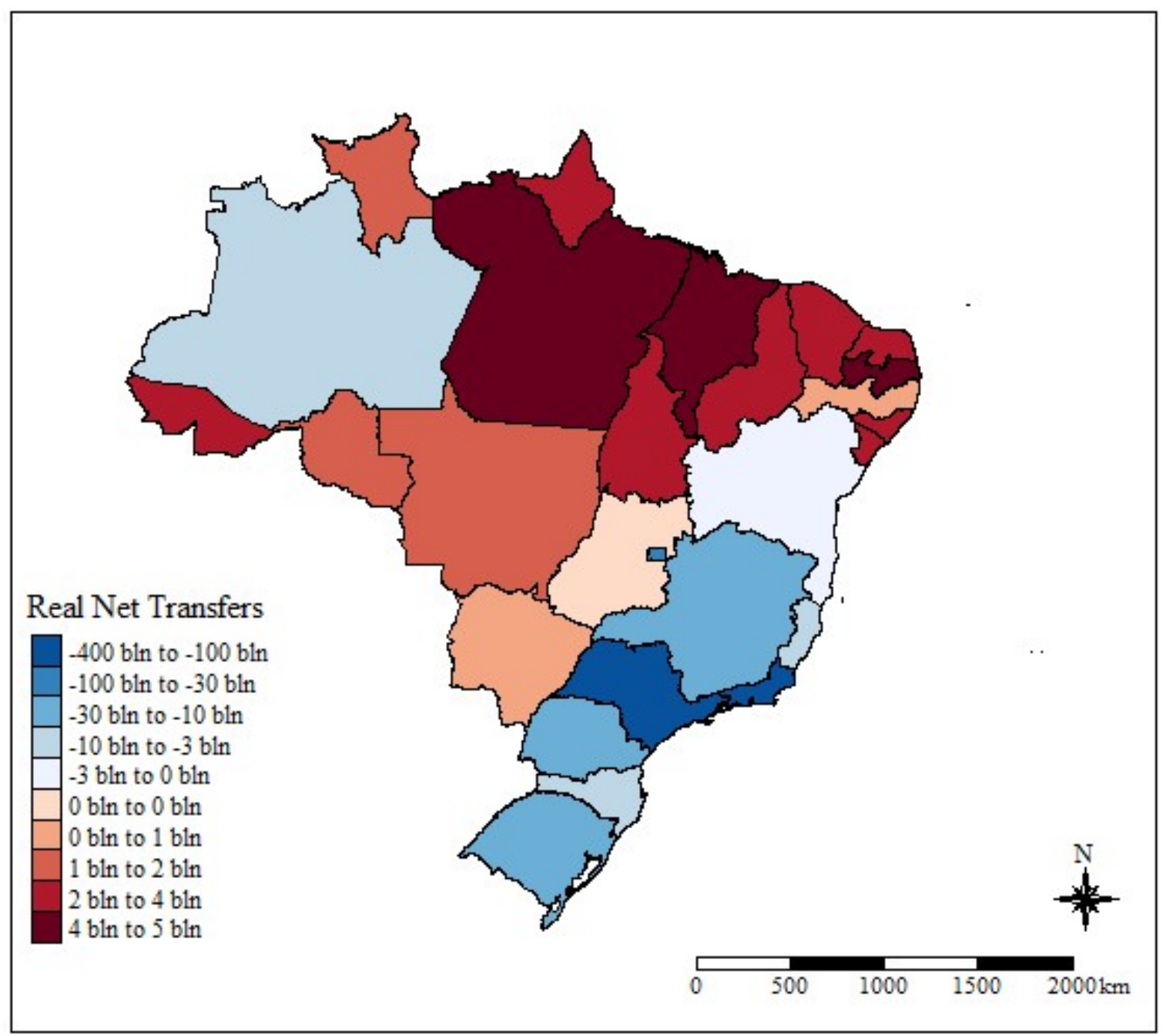

Notes: Real Net Transfers received by each Brazilian State on 2002. The values on the subtitles are in R\$, and bln is the abbreviation of "billions".

Source: Self elaboration, with use of IBGE, National Treasure and Federal Revenue data. 


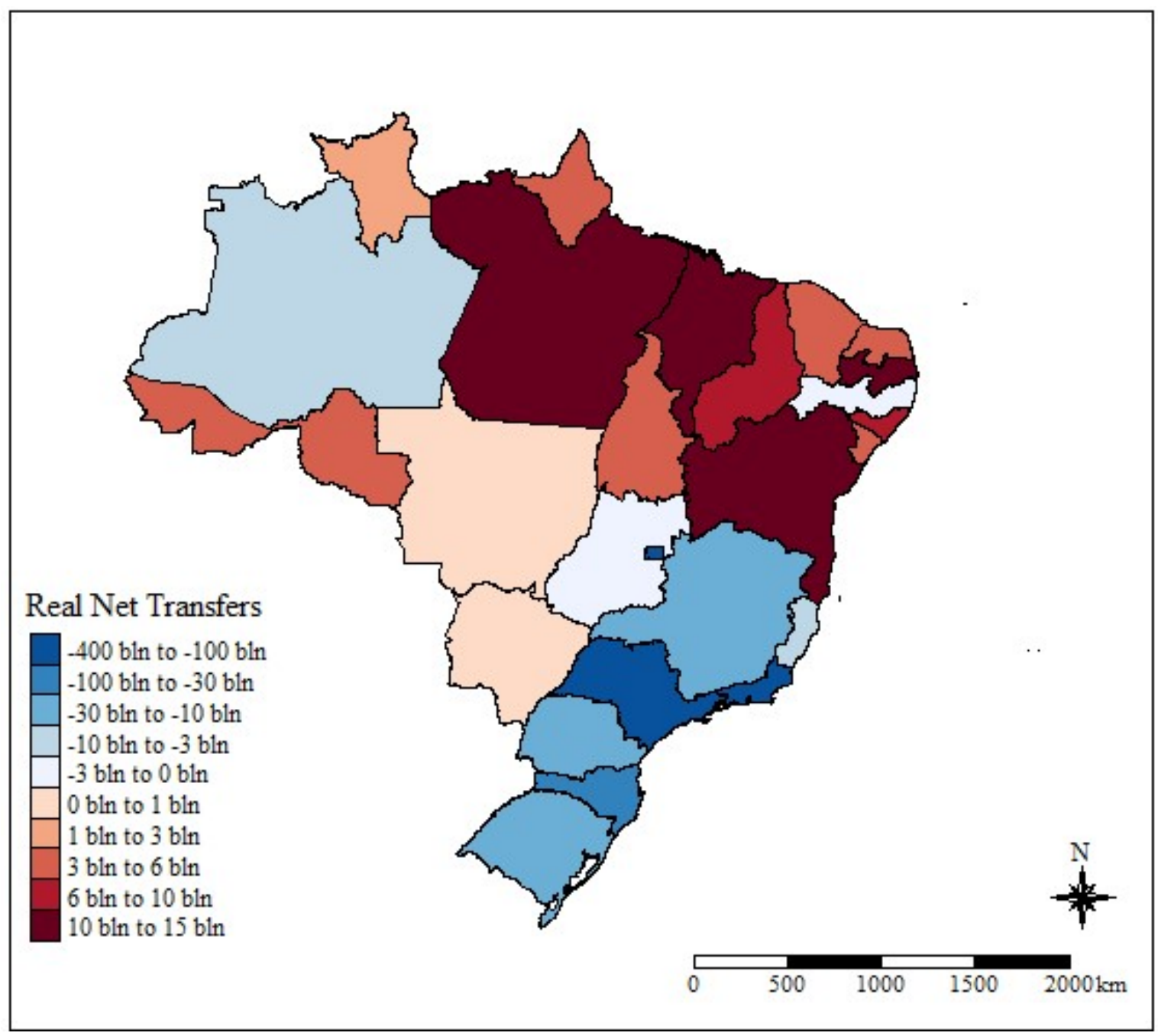

Notes: Real Net Transfers received by each Brazilian State on 2019. The values on the subtitles are in R\$, and bln is the abbreviation of "billions".

Source: Self elaboration, with use of IBGE, National Treasure and Federal Revenue data.

The blue states on the maps represent the net tax payers, while the red ones are the net receivers. Notice that the role of each state has not changed much when we compare 2002 to 2019, as only three states have switched between red and blue. This is evidence of income redistribution from the southern states (and Amazonas) to the northern. The maps also point that the majority of the funds comes from two states, São Paulo and Rio de Janeiro.

One may argue that more populous states may present greater absolute values for real net transfers. So, to complement the analysis and support the idea of income redistribution from the south towards north, Table 12 informs the ratio of transfers and tax revenue to gross state product, while Table 13 presents per capita transfers and tax revenue. In 
order to see the behavior of the values over time they are reported for three different years: 2002, 2010 and 2017.

Table 12: Transfers and tax revenue relative to state income

\begin{tabular}{|c|c|c|c|c|c|c|}
\hline & \multicolumn{2}{|c|}{2002} & \multicolumn{2}{|c|}{2010} & \multicolumn{2}{|c|}{2017} \\
\hline State & Transf/GSP & Rev/GSP & Transf/GSP & Rev/GSP & Transf/GSP & Rev/GSP \\
\hline $\mathrm{AC}$ & $31.57 \%$ & $3.07 \%$ & $27.88 \%$ & $3.87 \%$ & $28.26 \%$ & $4.81 \%$ \\
\hline AL & $14.68 \%$ & $3.57 \%$ & $17.13 \%$ & $4.46 \%$ & $14.87 \%$ & $5.08 \%$ \\
\hline $\mathbf{A M}$ & $7.60 \%$ & $14.81 \%$ & $7.69 \%$ & $14.78 \%$ & $9.50 \%$ & $14.17 \%$ \\
\hline $\mathbf{A P}$ & $28.18 \%$ & $4.18 \%$ & $26.77 \%$ & $3.23 \%$ & $23.76 \%$ & $5.38 \%$ \\
\hline BA & $10.44 \%$ & $10.48 \%$ & $10.47 \%$ & $8.21 \%$ & $10.43 \%$ & $7.37 \%$ \\
\hline $\mathrm{CE}$ & $12.44 \%$ & $7.72 \%$ & $12.41 \%$ & $8.85 \%$ & $11.24 \%$ & $8.90 \%$ \\
\hline DF & $0.49 \%$ & $49.14 \%$ & $0.40 \%$ & $43.99 \%$ & $1.22 \%$ & $45.95 \%$ \\
\hline ES & $5.84 \%$ & $11.91 \%$ & $6.25 \%$ & $14.59 \%$ & $7.90 \%$ & $12.95 \%$ \\
\hline GO & $5.70 \%$ & $5.25 \%$ & $6.00 \%$ & $7.54 \%$ & $5.74 \%$ & $6.45 \%$ \\
\hline MA & $19.06 \%$ & $7.44 \%$ & $18.81 \%$ & $6.92 \%$ & $18.02 \%$ & $6.52 \%$ \\
\hline MG & $5.68 \%$ & $10.84 \%$ & $5.69 \%$ & $10.08 \%$ & $5.63 \%$ & $8.65 \%$ \\
\hline MS & $6.07 \%$ & $3.86 \%$ & $6.52 \%$ & $4.19 \%$ & $5.56 \%$ & $4.78 \%$ \\
\hline MT & $7.61 \%$ & $4.35 \%$ & $7.26 \%$ & $4.67 \%$ & $5.87 \%$ & $5.05 \%$ \\
\hline PA & $11.17 \%$ & $5.04 \%$ & $10.91 \%$ & $3.53 \%$ & $10.81 \%$ & $4.18 \%$ \\
\hline PB & $16.42 \%$ & $5.41 \%$ & $16.21 \%$ & $5.38 \%$ & $14.96 \%$ & $6.40 \%$ \\
\hline PE & $9.66 \%$ & $8.97 \%$ & $10.18 \%$ & $10.13 \%$ & $9.22 \%$ & $10.31 \%$ \\
\hline PI & $24.96 \%$ & $5.67 \%$ & $21.86 \%$ & $5.12 \%$ & $18.88 \%$ & $5.62 \%$ \\
\hline PR & $4.68 \%$ & $12.29 \%$ & $4.90 \%$ & $14.26 \%$ & $4.74 \%$ & $11.00 \%$ \\
\hline RJ & $3.49 \%$ & $25.58 \%$ & $4.74 \%$ & $31.14 \%$ & $4.20 \%$ & $25.88 \%$ \\
\hline RN & $14.60 \%$ & $5.04 \%$ & $13.74 \%$ & $5.10 \%$ & $12.76 \%$ & $5.80 \%$ \\
\hline RO & $13.50 \%$ & $4.72 \%$ & $11.45 \%$ & $3.82 \%$ & $10.57 \%$ & $4.82 \%$ \\
\hline RR & $29.05 \%$ & $4.34 \%$ & $25.23 \%$ & $3.68 \%$ & $24.19 \%$ & $5.86 \%$ \\
\hline $\mathbf{R S}$ & $4.54 \%$ & $12.31 \%$ & $4.78 \%$ & $13.14 \%$ & $4.51 \%$ & $11.56 \%$ \\
\hline SC & $4.32 \%$ & $9.37 \%$ & $4.26 \%$ & $13.80 \%$ & $4.15 \%$ & $14.29 \%$ \\
\hline SE & $14.93 \%$ & $5.53 \%$ & $14.96 \%$ & $5.26 \%$ & $15.87 \%$ & $5.95 \%$ \\
\hline SP & $2.42 \%$ & $23.01 \%$ & $2.83 \%$ & $21.31 \%$ & $2.70 \%$ & $21.24 \%$ \\
\hline TO & $27.54 \%$ & $2.69 \%$ & $21.95 \%$ & $3.58 \%$ & $18.18 \%$ & $3.95 \%$ \\
\hline
\end{tabular}

Notes: Ratio of transfers and tax revenue to income for each Brazilian state for the years of 2002, 2010 and 2017.

Source: Self elaboration, with use of IBGE, National Treasure and Federal Revenue data. 
Table 13: Per capita transfers and tax revenue per Brazilian state

\begin{tabular}{|c|c|c|c|c|c|c|}
\hline & \multicolumn{2}{|c|}{2002} & \multicolumn{2}{|c|}{2010} & \multicolumn{2}{|c|}{2017} \\
\hline State & Transf. Pc & Rev. Pc & Transf. Pc & Rev. Pc & Transf. Pc & Rev. Pc \\
\hline $\mathrm{AC}$ & 4055.22 & 394.01 & 4426.25 & 614.48 & 4372.26 & 744.71 \\
\hline AL & 1669.39 & 406.08 & 2337.70 & 608.96 & 2105.65 & 718.64 \\
\hline AM & 1235.84 & 2410.44 & 1605.43 & 3086.38 & 1833.85 & 2736.40 \\
\hline $\mathbf{A P}$ & 4665.43 & 692.58 & 5412.80 & 653.05 & 4309.57 & 975.60 \\
\hline $\mathbf{B A}$ & 1361.44 & 1366.28 & 1751.09 & 1373.94 & 1604.54 & 1134.51 \\
\hline $\mathbf{C E}$ & 1421.81 & 882.64 & 1756.14 & 1252.16 & 1620.30 & 1283.92 \\
\hline DF & 315.38 & 31740.63 & 296.38 & 32989.36 & 865.70 & 32588.25 \\
\hline ES & 1121.20 & 2287.02 & 1614.69 & 3768.72 & 1878.65 & 3077.94 \\
\hline GO & 1175.75 & 1083.05 & 1545.42 & 1943.23 & 1450.99 & 1629.30 \\
\hline MA & 1541.93 & 602.05 & 2007.89 & 738.89 & 2039.05 & 737.47 \\
\hline MG & 1167.27 & 2227.33 & 1440.60 & 2551.19 & 1346.55 & 2067.81 \\
\hline MS & 1449.46 & 922.23 & 1908.27 & 1226.09 & 1769.75 & 1521.67 \\
\hline MT & 1592.90 & 909.76 & 2065.69 & 1328.33 & 1970.99 & 1694.17 \\
\hline$\overline{\mathbf{P A}}$ & 1515.28 & 683.34 & 1808.93 & 585.30 & 1830.13 & 707.81 \\
\hline PB & 1662.49 & 548.11 & 2138.19 & 710.11 & 2068.51 & 884.70 \\
\hline PE & 1335.80 & 1240.87 & 1697.44 & 1687.96 & 1521.36 & 1700.25 \\
\hline $\mathbf{P I}$ & 1974.44 & 448.65 & 2415.12 & 565.05 & 2375.24 & 707.40 \\
\hline PR & 1258.72 & 3307.61 & 1626.63 & 4735.21 & 1531.12 & 3555.00 \\
\hline RJ & 1104.59 & 8092.79 & 1694.52 & 11133.50 & 1415.52 & 8717.45 \\
\hline RN & 2243.44 & 774.57 & 2386.37 & 884.93 & 2087.59 & 949.29 \\
\hline RO & 2156.19 & 753.79 & 2664.73 & 887.64 & 2299.56 & 1049.06 \\
\hline RR & 5254.47 & 785.38 & 5431.79 & 791.99 & 5175.53 & 1254.45 \\
\hline$\overline{\mathrm{RS}}$ & 1244.44 & 3375.68 & 1544.03 & 4239.52 & 1462.45 & 3745.73 \\
\hline $\mathrm{SC}$ & 1297.74 & 2811.98 & 1466.48 & 4748.57 & 1386.11 & 4773.61 \\
\hline SE & 2123.54 & 786.54 & 2700.22 & 949.42 & 2525.17 & 946.90 \\
\hline SP & 822.69 & 7812.97 & 1219.26 & 9177.64 & 1069.08 & 8411.44 \\
\hline TO & 3534.20 & 345.17 & 4140.13 & 674.56 & 3616.93 & 785.66 \\
\hline
\end{tabular}

Notes: Per capita transfers and tax revenue for each Brazilian state. The values were deflated using state price indexes and are on $2017 \mathrm{R} \$$ values.

Source: Self elaboration, with use of IBGE, National Treasure and Federal Revenue data.

The tables above, indicate a better measure of the size of the redistribution per state, as now data is reported as a ratio to the state product in one table and on per capita terms on the other, so the size of the state effect is removed. To reinforce the idea of income redistribution from the south towards north, consider two different states: São Paulo (SP), which was colored indigo both on Figure 1 and Figure 2, and Pará (PA), which was colored dark red on both figures.

From Table 12, we acknowledge that São Paulo pays a much higher rate of its GSP on taxes than it receives on transfers over the three years reported, while Pará pays a smaller ratio than it receives. A similar result is pointed by Table 13, as more taxes are collected then returned in transfers to São Paulo on per capita terms over all the years on the table, while the opposite is true for Pará. 
For both tables, we could notice that the difference from the relative transfers and revenue columns for SP, RJ, and DF is significantly big for each year reported on Table 12. The same is valid for Table 13, in which per capita revenue is considerably higher then transfers for those states. However, there is a distortion for the Federal District (DF). As most of its workers are employees of the government, their salaries comes from the federal budget but are not counted as transfers, and the taxes collected from their income is accounted as tax revenues.

\subsection{Methodology and Results}

\subsubsection{Sala-i Martin and Sachs (1991) Model}

Recall that we want to estimate $\lambda$, which in this model is interpreted as the effect of net fiscal transfers on disposable income, and is a function of the elasticities of taxes and transfers in relation to variations in income, which are the coefficients of equations (29) and (30). As in Postali and Rocha (2003), we run panel regressions due to the short time dimension of the data. The equations estimated are given by:

$$
\ln \left(\frac{T X_{i t}}{T X_{t}}\right)=\alpha_{T X}+\beta_{T X} \ln \left(\frac{Y_{i t}}{Y_{t}}\right)+\mu_{i t},
$$

and

$$
\ln \left(\frac{T R_{i t}}{T R_{t}}\right)=\alpha_{T R}+\beta_{T R} \ln \left(\frac{Y_{i t}}{Y_{t}}\right)+\epsilon_{i t} .
$$

First, the equation is estimated by OLS, and then, due to the econometric issues highlighted on section 3.1.1, we run an Instrumental Variable estimation using the lagged GSP as instrument.

\section{Estimation Results}

The tables below resumes the parameters estimated from panel regressions of equations (38) and (39). Notice we run random effect models. 
Table 14: Tax elasticities

\begin{tabular}{|c|ccc|}
\hline Method & $\beta_{T X}$ & $\mathrm{sd}\left(\beta_{T X}\right)$ & $R^{2}$ \\
\hline OLS & 1.256 & 0.091 & 0.281 \\
IV & 1.533 & 0.114 & 0.267 \\
\hline
\end{tabular}

Notes: OLS and IV estimates of tax revenue elasticity (Equation 38). The lagged value of GSP was used as an instrument for the IV estimation. Source: Self elaboration, with use of IBGE and National Treasury data. Data period : 2000-2017.

Table 15: Transfers elasticities

\begin{tabular}{|c|ccc|}
\hline Method & $\beta_{T R}$ & $\mathrm{sd}\left(\beta_{T R}\right)$ & $R^{2}$ \\
\cline { 1 - 3 } & -0.417 & 0.047 & 0.122 \\
\cline { 1 - 1 } IV & -0.590 & 0.065 & 0.100 \\
\hline
\end{tabular}

Notes: OLS and IV estimates of federal transfers to states elasticity (Equation 39). The lagged value of GSP was used as an instrument for the IV estimation. Source: Self elaboration, with use of IBGE and Federal Revenue data. Data period : 2000-2017.

From Table 14 and Table 15 we perceive that all the coefficients are significant at a $1 \%$ level. All coefficient signs are as expected, so taxes increase with income while transfers decreases. This means that the net transfers are countercyclical, so they work as stabilizers in face of regional shocks. As the data are on log levels, the coefficients represents elasticities, so when gsp raises $1 \%$, tax collection raises around $1.25 \%$ to $1.53 \%$, while transfers reduces about $0.42 \%$ to $0.59 \%$. Those results are in line with Postali and Rocha (2003), and they are evidence of a certain degree of progressiveness on federal taxes. Notice that similar results are found by Sala-i Martin and Sachs (1991) for United States.

As highlighted by Postali and Rocha (2003), the redistribute aspect of Brazilian fiscal system may be reflected on equation (39) estimation results. To try to control for this problem, we follow the authors procedure and re-estimate the equation assuming a fixed effects model, allowing the parameter $\left(\alpha_{T R}\right)$ to vary within states, capturing fixed regional effects. The results are reported on the table below. 
Table 16: Transfers elasticities estimation with state fixed effects

\begin{tabular}{|c|c|c|c|c|}
\hline & \multicolumn{2}{|r|}{ OLS } & \multicolumn{2}{|r|}{ IV } \\
\hline & Coefficient & Standard Deviation & Coefficient & Standard Deviation \\
\hline$\beta_{T R}$ & -0.211 & 0.050 & -0.316 & 0.141 \\
\hline$A C$ & 1.074 & 0.040 & 1.011 & 0.089 \\
\hline$A L$ & 0.161 & 0.047 & 0.081 & 0.111 \\
\hline$A M$ & 0.058 & 0.032 & 0.023 & 0.054 \\
\hline$A P$ & 1.225 & 0.029 & 1.200 & 0.043 \\
\hline$B A$ & -0.095 & 0.038 & -0.151 & 0.079 \\
\hline$C E$ & -0.104 & 0.045 & -0.179 & 0.104 \\
\hline$D F$ & -1.072 & 0.054 & -0.974 & 0.134 \\
\hline$E S$ & 0.121 & 0.030 & 0.093 & 0.046 \\
\hline$G O$ & -0.089 & 0.028 & -0.104 & 0.034 \\
\hline$M A$ & 0.023 & 0.058 & -0.084 & 0.146 \\
\hline$M G$ & -0.142 & 0.027 & -0.144 & 0.027 \\
\hline$M S$ & 0.118 & 0.027 & 0.119 & 0.027 \\
\hline$M T$ & 0.199 & 0.027 & 0.187 & 0.031 \\
\hline$P A$ & 0.005 & 0.039 & -0.054 & 0.083 \\
\hline$P B$ & 0.136 & 0.048 & 0.054 & 0.114 \\
\hline$P E$ & -0.006 & 0.028 & 0.007 & 0.033 \\
\hline$P I$ & 0.238 & 0.038 & 0.182 & 0.080 \\
\hline$P R$ & -0.265 & 0.057 & -0.371 & 0.145 \\
\hline$R J$ & 0.009 & 0.031 & 0.039 & 0.049 \\
\hline$R N$ & 0.288 & 0.037 & 0.236 & 0.075 \\
\hline$R O$ & 0.486 & 0.028 & 0.504 & 0.037 \\
\hline$R R$ & 1.331 & 0.032 & 1.295 & 0.055 \\
\hline$R S$ & -0.152 & 0.032 & -0.191 & 0.058 \\
\hline$S C$ & -0.038 & 0.029 & -0.015 & 0.040 \\
\hline$S E$ & 0.673 & 0.033 & 0.714 & 0.061 \\
\hline$S P$ & -0.480 & 0.035 & -0.527 & 0.068 \\
\hline TO & 0.839 & 0.039 & 0.779 & 0.085 \\
\hline$R^{2}$ & & 0.031 & & 0.031 \\
\hline
\end{tabular}

Notes: Estimation of equation (39) with state fixed effects. The results are reported for both OLS and IV estimation. Source: Self elaboration, with use of IBGE and Federal Revenue and National Treasure data. Data period : 2000-2017.

From Table 16, we notice that the estimations of the elasticity of transfers to income reduces a little in absolute value when we introduce state fixed effects, but it remains significant and keeps the negative sign. It is also possible to note that most of the states with negative values for $\alpha_{T R}$ are colored in blue on figures 1 and 2 , which are net tax payers. This reflects the redistributive role of the tax-transfer system. The new $\beta_{T R}$ estimated values could be interpreted as the stabilization effect of the transfers, which, depending on the estimation method, is of $0.211 \%$ to $0.316 \%$ of raise (fall) on transfers for every $1 \%$ fall (raise) on state product. 
With the estimated values of $\beta_{T X}$ and $\beta_{T R}$, we could calculate the effect of net fiscal transfers on the regional disposable income. Following equation (25), the effect for state $i$ is given by:

$$
\lambda_{i}=1-\beta_{T X} \frac{T X_{i}}{Y_{i}}+\beta_{T R} \frac{T R_{i}}{Y_{i}} .
$$

Notice that the equation above is not indexed in time, so it is assumed that $\lambda$ does not change over time, only across states. As a panel model was estimated for the elasticities, the values for $\beta_{T X}$ and $\beta_{T R}$ are the same for all states. For the values of taxes and transfer relative to state product $\left(\frac{T X_{i}}{Y_{i}}\right.$ and $\left.\frac{T R_{i}}{Y_{i}}\right)$, we calculate it for each state and take the mean value over time. Table 17 displays the values of $\lambda$ for each state for both estimation methods used. We also disaggregate the effect into taxes and transfers, reporting the values of $-\beta_{T X} \frac{T X_{i}}{Y_{i}}$ (Taxes) and $\beta_{T R} \frac{T R_{i}}{Y_{i}}$ (Transfers). Recall that $\lambda$ in interpreted as the fraction of the variation on current product that is translated to disposable income after taxes and transfers, so the lower the value of $\lambda$ the more smoothing is achieved, and $(1-\lambda)$ could be interpreted as a measure of risk sharing via fiscal federalism. 
Table 17: Effect of net fiscal transfers on the regional disposable income

\begin{tabular}{|c|c|c|c|c|c|c|}
\hline \multirow{2}{*}{ State } & \multicolumn{3}{|c|}{ OLS } & \multicolumn{3}{|c|}{ IV } \\
\hline & $\lambda$ & Transfers & Taxes & $\lambda$ & Transfers & Taxes \\
\hline$A C$ & 0.887 & -0.080 & $\begin{array}{l}-0.032 \\
-0.03\end{array}$ & 0.847 & -0.113 & -0.040 \\
\hline$A L$ & 0.924 & -0.042 & -0.035 & 0.899 & -0.059 & -0.042 \\
\hline$A M$ & 0.850 & -0.023 & -0.127 & 0.813 & -0.032 & -0.155 \\
\hline$A P$ & 0.901 & -0.067 & -0.032 & 0.867 & -0.094 & -0.039 \\
\hline$B A$ & 0.914 & -0.026 & -0.060 & 0.890 & -0.037 & -0.073 \\
\hline$C E$ & 0.905 & -0.030 & -0.065 & 0.878 & -0.043 & -0.079 \\
\hline$D F$ & 0.606 & -0.002 & -0.392 & 0.519 & -0.003 & -0.478 \\
\hline$E S$ & 0.808 & -0.026 & -0.166 & 0.760 & -0.037 & -0.203 \\
\hline$G O$ & 0.936 & -0.015 & -0.049 & 0.919 & -0.021 & -0.060 \\
\hline$M A$ & 0.904 & -0.047 & -0.049 & 0.873 & -0.067 & -0.060 \\
\hline$M G$ & 0.908 & -0.015 & -0.078 & 0.885 & -0.021 & -0.095 \\
\hline$M S$ & 0.949 & -0.016 & -0.036 & 0.934 & -0.022 & -0.043 \\
\hline$M T$ & 0.946 & -0.017 & -0.037 & 0.930 & -0.024 & -0.046 \\
\hline$P A$ & 0.940 & -0.028 & -0.032 & 0.921 & -0.039 & -0.039 \\
\hline$P B$ & 0.913 & -0.041 & -0.046 & 0.886 & -0.058 & -0.056 \\
\hline$P E$ & 0.900 & -0.024 & -0.076 & 0.873 & -0.034 & -0.092 \\
\hline$P I$ & 0.909 & -0.052 & -0.039 & 0.879 & -0.074 & -0.047 \\
\hline$P R$ & 0.890 & -0.012 & -0.098 & 0.864 & -0.017 & -0.119 \\
\hline$R J$ & 0.748 & -0.012 & -0.240 & 0.690 & -0.017 & -0.293 \\
\hline$R N$ & 0.925 & -0.034 & -0.041 & 0.901 & -0.049 & -0.050 \\
\hline$R O$ & 0.937 & -0.029 & -0.034 & 0.917 & -0.042 & -0.041 \\
\hline$R R$ & 0.889 & -0.072 & -0.039 & 0.851 & -0.102 & -0.048 \\
\hline$R S$ & 0.894 & -0.012 & -0.094 & 0.868 & -0.017 & -0.115 \\
\hline$S C$ & 0.886 & -0.011 & -0.103 & 0.859 & -0.015 & -0.126 \\
\hline$S E$ & 0.913 & -0.042 & -0.045 & 0.885 & -0.059 & -0.055 \\
\hline$S P$ & 0.820 & -0.007 & -0.173 & 0.779 & -0.010 & -0.211 \\
\hline TO & 0.916 & -0.056 & -0.029 & 0.887 & -0.079 & -0.035 \\
\hline Avegare & 0.886 & -0.031 & -0.083 & 0.855 & -0.044 & -0.102 \\
\hline
\end{tabular}

Notes: Effects of net fiscal transfers on regional disposable income per state for each estimation method used on equations 38 and 39. $\lambda$ (first column) is the multiplier of the effect of net fiscal transfer on disposable income, while the following columns disaggregates the effects of transfers and taxes on income smoothing, respectively. The results are reported based on the elasticities estimated with OLS and with IV. Source: Self elaboration, with use of IBGE and Federal Revenue and National Treasure data.Data period : 2000-2017.

As all the values of $\lambda$ are smaller than 1, there is evidence that the fiscal system acts in order to cushion the effects of income shocks on all states. The results suggests that the smoothing effects are higher on the wealthier states, which is probably due to the fact that a higher proportion of its product is collected on taxes, amplifying the effect of taxation, which is the main source of risk sharing through the fiscal channel for those states. The average values for $\lambda$ are 0.886 for OLS estimation and 0.855 ofr IV estimation, which suggests that 
fiscal federalism reduces the impacts of shocks on state product on around $13 \%$.

\subsubsection{Asdrubali et al.'s (1996) Model Estimation Results}

This section presents and discusses the estimation of equations from Asdrubali et al. ss (1996) model. Recall that the model equations (35-37) are:

$$
\begin{gathered}
\Delta \log \left(g s p_{i t}\right)-\Delta \log \left(d s i_{i t}\right)=v_{F, t}+\beta_{F} \Delta \log \left(g s p_{i t}\right)+\epsilon_{F, i t}, \\
\Delta \log \left(d s i_{i t}\right)-\Delta \log \left(c_{i t}\right)=v_{C, t}+\beta_{C} \Delta \log \left(g s p_{i t}\right)+\epsilon_{C, i t}, \\
\Delta \log \left(c_{i t}\right)=v_{\mu, t}+\beta_{\mu} \Delta \log \left(g s p_{i t}\right)+\epsilon_{\mu, i t} .
\end{gathered}
$$

Recall that $v$ represents a time fixed effect. Notice we run a panel "fixed effects" model estimation for each equation. As pointed on the descriptive statistics of income data on chapter 2 (table 1), the states presents significant differences on the variance of state product, so we have take into consideration that our equations may suffer of heterocedasticity problem. To handle this issue, the equations above are estimated by a two step Generalized Least Squares (GLS) procedure, as in Asdrubali et al. (1996) and Sørensen et al. (2007).

The data used for $g s p$ is our constructed per capita gross state product, the same data used to estimate the previous models. For $d s i$, we use disposable state income, which was calculated summing per capita net transfers to per capita gross state product. Finally, as $c$ we use per capita real retail sales. The table below report the estimated percentages of income shocks absorbed by the federal tax/transfers system and other channels and also the percentage of non smoothed shocks. The standard errors are presented on the brackets. 
Table 18: Effect of Net Fiscal Transfers on the Regional Disposable Income

\begin{tabular}{|c|c|}
\hline Fiscal Federalism $\left(\beta_{F}\right)$ & $\begin{array}{l}13.85 \% \\
(1.74 \%)\end{array}$ \\
\hline Other Channels $\left(\beta_{C}\right)$ & $\begin{array}{l}21.07 \% \\
(5.37 \%)\end{array}$ \\
\hline Non Smoothed $\left(\beta_{\mu}\right)$ & $\begin{array}{l}64.02 \% \\
(5.16 \%)\end{array}$ \\
\hline
\end{tabular}

Notes: Percentages of shocks absorbed at each level of smoothing. Standard errors in brackets. Data source: IBGE, Federal Revenue and National Treasury. Data period : 2002-2017.

Notice from table 15 that all the results are statistically significant. As a GLS procedure was used for the estimation, the coefficients do not sum 1 since the regressors became different at each equation as they are corrected by the variance-covariance matrix.

The estimation results points that $64,02 \%$ of the shocks to gross state product are not smoothed. The coefficient $\left(\beta_{\mu}\right)$ is statistically significant, which is evidence against complete risk sharing. We also find that $13,85 \%$ of the shocks are smoothed by the federal government taxes and transfers $\left(\beta_{F}\right)$, while $21,07 \%\left(\beta_{C}\right)$ are smoothed by other channels.

Notice those the finding of a $13,85 \%$ risk reduction via the fiscal channel is in line with what the estimation of last section model pointed. However, the results are not matched with the findings from chapter 2 , as they point to a much lower degree of risk sharing. Recall that our last chapter risk sharing equation encompass aggregate consumption growth as a regressor, so the lack of control for this variable may be an explanation for the difference on the results.

Meantime, we could imply from this chapter results that despite the expected redistribute feature of Brazilian fiscal federalism, the tax-transfer system acts as a stabilizer, but is not responsible for the majority of risk sharing withing the country, smoothing a fraction of around $13 \%$ of regional income shocks. 


\section{Final Remarks}

Despite the literature on risk sharing being rich, there is only a few papers that focus on the Brazilian regional case. In light of that, this dissertation pursued to analyze this subject. This study has measured the degree of consumption risk sharing among the Brazilian states and MERCOSUL countries, in order to compare the regional and international results. The empirical analysis also gives special focus to the role of fiscal federalism as a channel of risk sharing.

First, we have examined the degree of consumption synchronicity among Brazilian states based on a model of incomplete risk sharing, following the analysis of Crucini (1999) and Asdrubali and Kim (2008). The models were also estimated for the MERCOSUL countries, allowing the comparison of the degree of risk sharing at regional and international levels.

The second part of this study has focused on the role of fiscal federalism as a mechanism of risk sharing. We based the analysis on Sala-i Martin and Sachs (1991) and Asdrubali et al. (1996). A first overview of the data pointed that there is a consistent outflow of funds from the southern to the northern states over time. This suggests that the fiscal federalism is pursuing income redistribution, and not only income smoothing. A behavior like that is expected from the central government as there is a strong income inequality among the states.

On the first step of Sala-i Martin and Sachs s (1991) model estimation, we calculate the elasticities of taxes and transfers in response to variations on the product. From those values, a multiplier of the effects of regional income shocks to disposable income after taxes and transfers was calculated. A further analysis of the role of the tax-transfer system was realized with a variance decomposition of regional income shocks, a procedure that is proposed by Asdrubali et al. (1996).

The results suggested a high degree of risk sharing for the Brazilian regional case, with an estimated degree of around $86 \%$. However, there is no evidence in favor of complete risk sharing, implying that there is still scope for risk sharing. The results for the degree of risk sharing of Brazil with MERCOSUL countries were very sensible to the procedures used to estimate it, varying from no risk sharing to a degree of around $43 \%$. The main conclusion of those results is that there is a higher degree of risk sharing on the regional case in comparison to the international level, as is predicted from the theory, which states that the regional case may present a lower level of barriers for integration, and the federal government 
has the power to move funds across states, reducing regional risks.

The part of the results that touches the fiscal federalism role on risk sharing pointed to a reduction of around $13 \%$ of the effects of idiosyncratic shocks via the tax and transfer system. However, the most significant volatility reduction is due to the taxes and nor to the transfers, reflecting the progressiveness of federal taxes. The analysis of the data and the results also point to a significant redistributive role of this system, with an inflow of funds from the south to the north of the country, regardless of negative shocks.

Despite this study pointing to a high degree of integration among Brazilian states consumption, there is still scope for more risk sharing and thus for welfare gains. A higher degree of risk sharing would be achieved with a better development of the federal transfers strategy, as they do not respond much to variations on regional income and are focused on the redistributive role.

Additionally the results of a low integration of the country with MERCOSUL countries suggests that not much of the aggregate risks are being shared. Even though the results pointed that most of the risks are shared within the country, the aggregate level shocks inside the country could only be shared with other nations. So policies that seek better integration with MERCOSUL countries could lead to welfare improvements, as it will enable the country to share risks that could not be shared regionally. 


\section{References}

Arrow, K. J. (1973). The role of securities in the optimal allocation of risk-bearing. In Readings in Welfare Economics, pp. 258-263. Springer.

Asdrubali, P. and S. Kim (2008). Incomplete intertemporal consumption smoothing and incomplete risk sharing. Journal of Money, Credit and Banking 40(7), 1521-1531.

Asdrubali, P., B. E. Sørensen, and O. Yosha (1996). Channels of interstate risk sharing: United states 1963-1990. The Quarterly Journal of Economics 111(4), 1081-1110.

Athanasoulis, S. G. and E. v. Wincoop (2001). Risk sharing within the united states: What do financial markets and fiscal federalism accomplish? Review of Economics and Statistics 83(4), 688-698.

Atkeson, A. and T. Bayoumi (1993). Do private capital markets insure regional risk? evidence from the united states and europe. Open Economies Review 4(3), 303-324.

Campbell, J. Y. and N. G. Mankiw (1989). Consumption, income, and interest rates: Reinterpreting the time series evidence. NBER macroeconomics annual 4, 185-216.

Cimadomo, J., O. Furtuna, and M. Giuliodori (2018). Private and public risk sharing in the euro area.

Cochrane, J. H. (1991). A simple test of consumption insurance. Journal of political economy $99(5), 957-976$.

Cossío, F. A. B. (1998). Disparidades econômicas inter-regionais, capacidade de obtenção de recursos tributários, esforço fiscal e gasto público no federalismo brasileiro.

Crucini, M. J. (1999). On international and national dimensions of risk sharing. Review of Economics and Statistics 81(1), 73-84.

Crucini, M. J. and G. D. Hess (2000). International and intranational risk sharing. Intranational macroeconomics, 37-59.

Debreu, G. (1959). Theory of Value An Aziomatic Analysis of Economic Equilibrium. Cowles Foundation Yale University PO Box 208281 New Haven CT 06520-8281.

Du, J., Q. He, and O. M. Rui (2011). Channels of interprovincial risk sharing in china. Journal of Comparative Economics 39(3), 383-405. 
Feyrer, J. and B. Sacerdote (2013). How much would us style fiscal integration buffer european unemployment and income shocks?(a comparative empirical analysis). American Economic Review 103(3), 125-28.

Flavin, M. A. (1981). The adjustment of consumption to changing expectations about future income. Journal of political economy 89(5), 974-1009.

Friedman, M. (1957). The permanent income hypothesis. In A theory of the consumption function, pp. 20-37. Princeton University Press.

Hess, G. D. and K. Shin (1998). Intranational business cycles in the united states. Journal of International Economics 44(2), 289-313.

Hill, R. C., W. E. Griffiths, and G. C. Lim (2018). Principles of econometrics. John Wiley \& Sons.

Ho, C.-Y., W.-Y. A. Ho, and D. Li (2015). Intranational risk sharing and its determinants. Journal of International Money and Finance 51, 89-113.

Kalemli-Ozcan, S., B. E. Sørensen, and O. Yosha (2003). Risk sharing and industrial specialization: Regional and international evidence. American Economic Review 93(3), 903-918.

León-Ledesma, M. A. and A. Mihailov (2010). Advanced international macroeconomics and finance oup book, chapter 5: Asset markets and risk sharing: Analytical introduction of uncertainty.

Martin, V., S. Hurn, and D. Harris (2013). Econometric modelling with time series: specification, estimation and testing. Cambridge University Press.

Mundell, R. A. (1961). A theory of optimum currency areas. The American economic review 51(4), 657-665.

Oliveira, L. H. H. and C. E. Carrasco-Gutierrez (2016). The dynamics of the brazilian current account with rule of thumb consumers. Economia Aplicada 20(2), 287-309.

Parsley, D. C. and H. Popper (2018). Blue states and red states: Business cycle divergence and risk sharing.

Persson, T. and G. Tabellini (1996). Federal fiscal constitutions: risk sharing and redistribution. Journal of political Economy 104(5), 979-1009. 
Poghosyan, T., A. Senhadji, and C. Cottarelli (2016). The role of fiscal transfers in smoothing regional shocks: Evidence from existing federations and implications for the euro area.

Postali, F. and F. Rocha (2003). Federalismo fiscal enquanto esquema de seguro regional: uma avaliação do caso brasileiro.

Rogoff, K. and M. Obstfeld (1996). Foundations of international macroeconomics.

Sala-i Martin, X. and J. Sachs (1991). Fiscal federalism and optimum currency areas: evidence for europe from the united states.

Sørensen, B. E., Y.-T. Wu, O. Yosha, and Y. Zhu (2007). Home bias and international risk sharing: Twin puzzles separated at birth. Journal of international money and finance 26(4), 587-605.

Sørensen, B. E. and O. Yosha (1998). International risk sharing and european monetary unification. Journal of International Economics 45(2), 211-238.

Stock, J. H. and M. Yogo (2002). Testing for weak instruments in linear iv regression.

Van Wincoop, E. (1995). Regional risksharing. European Economic Review 39(8), 1545-1567.

Van Wincoop, E. (1999). How big are potential welfare gains from international risksharing? Journal of International Economics 47(1), 109-135.

von Hagen, J. (2000). Fiscal policy and intranational risk sharing4. Intranational macroeconomics, 272.

Wooldridge, J. M. (2015). Introductory econometrics: A modern approach. Nelson Education. 


\section{Appendix A Derivation of Crucini's (1999) and Asdrubali and Kim's (2008) Risk Sharing Equations}

\section{A.1 Crucini's (1999) Risk Sharing Equation}

Crucinils (1999) model departs from a set of equations representing an income pooling mechanism and a consumption change rule equation based on Friedman s $\mathrm{s}$ (1957) permanent income model to arrive at a estimable risk sharing equation.

Recall that the income pooling mechanism is defined by the equations:

$$
\begin{gathered}
Y_{a t}=\frac{1}{\Lambda} \sum_{j=1}^{J} \lambda_{j} Y_{j t}, \\
\bar{Y}_{j t}=\lambda_{j} Y_{a t}+\left(1-\lambda_{j}\right) Y_{j t} .
\end{gathered}
$$

in which $\Lambda=\sum_{j=1}^{J} \lambda_{j}$.

The consumption decision rule is given by:

$$
\Delta C_{j t}=(1-\beta) \sum_{k=0}^{\infty} \beta^{k}\left[\mathbb{E}_{t} \bar{Y}_{j t+k}-\mathbb{E}_{t-1} \bar{Y}_{j t+k}\right] .
$$

To find the value of $Y_{a t}$, the values of each agent $\lambda$ are necessary. To deal with this problem, we assume that each agent contributes with the same income share, so $\lambda_{j}=\lambda$ for all agents $j$. Therefore we have that $\Lambda=J \lambda$, and substituting this equation on (40):

$$
Y_{a t}=\frac{1}{J \lambda} \sum_{j=1}^{J} \lambda Y_{j t}=\frac{1}{J} \sum_{j=1}^{J} Y_{j t} .
$$

We assume then that the aggregate change in consumption is the average growth over all agents, so we have that:

$$
\Delta C_{a t}=\frac{1}{J} \sum_{j=1}^{J} \Delta C_{j t}
$$

and substituting (42) in the equation above:

$$
\Delta C_{a t}=\frac{1}{J} \sum_{j=1}^{J}(1-\beta) \sum_{k=0}^{\infty} \beta^{k}\left[\mathbb{E}_{t} \bar{Y}_{j t+k}-\mathbb{E}_{t-1} \bar{Y}_{j t+k}\right] .
$$

Now substituting (41) on (44): 


$$
\begin{gathered}
\Delta C_{a t}=\frac{(1-\beta)}{J} \sum_{j=1}^{J} \sum_{k=0}^{\infty} \beta^{k}\left[\mathbb{E}_{t}\left(\lambda Y_{a t+k}+(1-\lambda) Y_{j t+k}\right)-\mathbb{E}_{t-1}\left(\left(\lambda Y_{a t+k}+(1-\lambda) Y_{j t+k}\right)\right],\right. \\
\Delta C_{a t}=\frac{(1-\beta)}{J} \sum_{j=1}^{J} \sum_{k=0}^{\infty} \beta^{k}\left(\lambda\left[\mathbb{E}_{t} Y_{a t+k}-\mathbb{E}_{t-1} Y_{a t+k}\right]+(1-\lambda)\left[\mathbb{E}_{t} Y_{j t+k}-\mathbb{E}_{t-1} Y_{j t+k}\right]\right), \\
\text { and summing the equation above over the agents } 12 \\
\Delta C_{a t}=\frac{(1-\beta)}{J} \sum_{k=0}^{\infty} \beta^{k}\left(\lambda J\left[\mathbb{E}_{t} Y_{a t+k}-\mathbb{E}_{t-1} Y_{a t+k}\right]+(1-\lambda) J\left[\mathbb{E}_{t} Y_{a t+k}-\mathbb{E}_{t-1} Y_{a t+k}\right]\right),
\end{gathered}
$$

which results in:

$$
\Delta C_{a t}=(1-\beta) \sum_{k=0}^{\infty} \beta^{k}\left[\mathbb{E}_{t} Y_{a t+k}-\mathbb{E}_{t-1} Y_{a t+k}\right] .
$$

From (42) we have that:

$$
\begin{gathered}
\Delta C_{j t}=(1-\beta) \sum_{k=0}^{\infty} \beta^{k}\left[\mathbb{E}_{t}\left(\lambda Y_{a t+k}+(1-\lambda) Y_{j t+k}\right)-\mathbb{E}_{t-1}\left(\lambda Y_{a t+k}+(1-\lambda) Y_{j t+k}\right)\right], \\
\Delta C_{j t}=(1-\beta) \sum_{k=0}^{\infty} \beta^{k} \lambda\left[\mathbb{E}_{t} Y_{a t+k}-\mathbb{E}_{t-1} Y_{a t+k}\right]+(1-\beta) \sum_{k=0}^{\infty} \beta^{k}(1-\lambda)\left[\mathbb{E}_{t} Y_{j t+k}-\mathbb{E}_{t-1} Y_{j t+k}\right],
\end{gathered}
$$

which finally results on

$$
\Delta C_{j t}=\lambda \Delta C_{a t}+(1-\lambda)(1-\beta) \sum_{k=0}^{\infty} \beta^{k}\left[\mathbb{E}_{t} Y_{j t+k}-\mathbb{E}_{t-1} Y_{j t+k}\right],
$$

that is equivalent to

$$
\Delta C_{j t}=\lambda \Delta C_{a t}+(1-\lambda) \Delta Y p_{j t} .
$$

\footnotetext{
${ }^{12}$ Notice we used the fact that $J Y_{a t}=\sum_{j=1}^{J} Y_{j t}$.
} 


\section{A.2 Asdrubali and Kim's (2008) Risk Sharing Equation}

This model also departs from the income pooling equations, so equations (40) and (41) are valid. Besides assuming that $\lambda$ is the same for all regions, it is also supposed that $\gamma$ is equal across regions. We have then:

$$
\begin{gathered}
\bar{Y}_{j t}=\lambda Y_{a t}+(1-\lambda) Y_{j t}, \\
Y_{a t}=\frac{1}{J} \sum_{j=1}^{J} Y_{j t}, \\
\Delta C_{a t}=\frac{1}{J} \sum_{j=1}^{J} \Delta C_{j t} .
\end{gathered}
$$

The difference from Crucini]s (1999), is that now only a fraction $\gamma$ of permanent income variation is used to smooth consumption, its change is a function of current income and permanent income $\left(\bar{\epsilon}_{j t}\right)$, so we have:

$$
\Delta C_{j t}=\mu_{j}+(1-\gamma) \Delta \bar{Y}_{j t}+\gamma \bar{\epsilon}_{j t}
$$

Aggregating equation (48) we have:

$$
\Delta C_{a t}=\sum_{j=1}^{J}\left(\mu_{j}+(1-\gamma) \Delta \bar{Y}_{j t}+\gamma \bar{\epsilon}_{j t}\right) J^{-1} .
$$

Notice that:

$$
\begin{gathered}
\frac{\sum_{j=1}^{J} \Delta \bar{Y}_{j t}}{J}=\frac{\sum_{j=1}^{J}\left[\lambda \Delta Y_{j t}+(1-\lambda) \Delta Y_{j t}\right]}{J} \\
=\frac{\lambda J \Delta Y_{a t}}{J}+\frac{(1-\lambda) \sum_{j=1}^{J} \Delta Y_{j t}}{J} \\
=\lambda \Delta Y_{a t}+\frac{(1-\lambda) J \Delta Y_{a t}}{J}=\Delta Y_{a t},
\end{gathered}
$$

so

$$
\frac{\sum_{j=1}^{J} \Delta \bar{Y}_{j t}}{J}=\Delta Y_{a t}
$$


Defining:

$$
\begin{gathered}
\mu \equiv \frac{\sum_{j=1}^{J} \mu_{j}}{J}, \\
\epsilon_{a t} \equiv \frac{\sum_{j=1}^{J} \epsilon_{j t}}{J},
\end{gathered}
$$

and using (50), (51) and (52) on equation (49) we have:

$$
\Delta C_{a t}=\mu+(1-\gamma) \Delta Y_{a t}+\epsilon_{a t}
$$

Now subtracting $\lambda$ times equation (53) from equation (48):

$$
\Delta C_{j t}-\lambda \Delta C_{a t}=\left(\mu_{j}-\mu\right)+(1-\gamma) \Delta \bar{Y}_{j t}-\lambda(1-\gamma) \Delta Y_{a t}+\gamma \bar{\epsilon}_{j t}-\lambda \gamma \epsilon_{a t} .
$$

Defining $\overline{\mu_{j}} \equiv\left(\mu_{j}-\mu\right)$ and $\epsilon_{j t} \equiv \gamma \overline{j_{j t}}-\lambda \gamma \epsilon_{a t}$, and substituting the expression for the first difference of $\bar{Y}_{j t}$ we have:

$$
\Delta C_{j t}=\bar{\mu}_{j}+\lambda \Delta C_{a t}+(1-\gamma)\left[\lambda \Delta Y_{a t}+(1-\lambda) \Delta Y_{j t}\right]-\lambda(1-\gamma) \Delta Y_{a t}+\epsilon_{j t},
$$

and simplifying the equation above we arrive at

$$
\Delta C_{j t}=\bar{\mu}_{j}+\lambda \Delta C_{a t}+(1-\gamma)(1-\lambda) \Delta Y_{j t}+\epsilon_{j t},
$$

as we wanted to show.

\section{Appendix B Demonstration of the permanent income revi- sion rule for the $\operatorname{VAR}(1)$ case}

This appendix demonstrates the proposition 1. Our income joint process is given by:

$$
\left(\begin{array}{c}
\Delta y_{a t} \\
\Delta y_{j t}
\end{array}\right)=\left(\begin{array}{cc}
A_{j}^{11} & A_{j}^{12} \\
A_{j}^{21} & A_{j}^{22}
\end{array}\right)\left(\begin{array}{c}
\Delta y_{a t-1} \\
\Delta y_{j t-1}
\end{array}\right)+\left(\begin{array}{c}
v_{a j t} \\
v_{j t}
\end{array}\right),
$$


which could be written in a matrix form: $\Delta \mathbf{Y}_{j t}=\mathbf{A}_{j} \Delta \mathbf{Y}_{j t-1}+\mathbf{V}_{j t}$, in which $\mathbf{Y}_{j t}=\left(\begin{array}{l}y_{a t} \\ y_{j t}\end{array}\right)$, $\Delta \mathbf{Y}_{j t}=\left(\begin{array}{c}\Delta y_{a t} \\ \Delta y_{j t}\end{array}\right), \mathbf{A}_{j}=\left(\begin{array}{cc}A_{j}^{11} & A_{j}^{12} \\ A_{j}^{21} & A_{j}^{22}\end{array}\right)$ and $\mathbf{V}_{j t}=\left(\begin{array}{c}v_{a j t} \\ v_{j t}\end{array}\right)$

According to chapter 13 of Martin et al. (2013), as we have a VAR(1) process, we could write it in a $V M A(\infty)$ form, given by: $\Delta \mathbf{Y}_{j t}=\sum_{i=0}^{\infty} \mathbf{A}_{j}^{i} \mathbf{V}_{t-i}$.

Taking the equation above $s$ periods forward we have $\Delta \mathbf{Y}_{j t+s}=\sum_{i=0}^{\infty} \mathbf{A}_{j}^{i} \mathbf{V}_{t+s-i}$, which is equivalent to $\mathbf{Y}_{j t+s}=\mathbf{Y}_{j t+s-1}+\sum_{i=0}^{\infty} \mathbf{A}_{j}^{i} \mathbf{V}_{t+s-i}$. Taking expectations at time $t$ and $t-1$, we have:

$$
\mathbb{E}_{t} \mathbf{Y}_{j t+s}=\mathbf{Y}_{j t+s-1}+\sum_{i=0}^{\infty} \mathbf{A}_{j}^{s+i} \mathbf{V}_{t-i}
$$

and

$$
\mathbb{E}_{t-1} \mathbf{Y}_{j t+s}=\mathbf{Y}_{j t+s-1}+\sum_{i=1}^{\infty} \mathbf{A}_{j}^{s+i} \mathbf{V}_{t-i}
$$

Finally, we have that:

$$
\mathbb{E}_{t} \mathbf{Y}_{j t+s}-\mathbb{E}_{t-1} \mathbf{Y}_{j t+s}=\mathbf{A}_{j}^{s} \mathbf{V}_{t}
$$

Recall that the revision on permanent income is given by:

$$
\Delta y p_{a t}=(1-\beta) \sum_{s=0}^{\infty} \beta^{s}\left(\mathbb{E}_{t} y_{a t+s}-\mathbb{E}_{t-1} y_{a t+s}\right)
$$

and

$$
\Delta y p_{j t}=(1-\beta) \sum_{s=0}^{\infty} \beta^{s}\left(\mathbb{E}_{t} y_{j t+s}-\mathbb{E}_{t-1} y_{j t+s}\right),
$$

for aggregate and regional case, respectively. So, we have that:

$$
\Delta \mathbf{Y p}_{j t}=(1-\beta) \sum_{s=0}^{\infty} \beta^{s}\left(\mathbb{E}_{t} \mathbf{Y}_{j t+s}-\mathbb{E}_{t-1} \mathbf{Y}_{j t+s}\right)
$$


in which $\boldsymbol{\Delta} \mathbf{Y} \mathbf{p}_{j t}=\left(\begin{array}{c}\Delta y p_{a t} \\ \Delta y p_{j t}\end{array}\right)$. Using equation (55):

$$
\boldsymbol{\Delta} \mathbf{Y} \mathbf{p}_{j t}=(1-\beta) \sum_{s=0}^{\infty}\left(\beta \mathbf{A}_{j}\right)^{s} \mathbf{V}_{t}
$$

Assuming that the matrix $\beta \mathbf{A}_{j}$ is invertible, the following is valid:

$$
\sum_{s=0}^{\infty}(\beta \mathbf{A})^{s}=\left(I-\beta \mathbf{A}_{j}\right)^{-1}
$$

we then have:

$$
\boldsymbol{\Delta} \mathbf{Y} \mathbf{p}_{j t}=(1-\beta)\left(I-\beta \mathbf{A}_{j}\right)^{-1} \mathbf{V}_{t},
$$

and denoting $\mathbf{B}_{j}=\left(I-\beta \mathbf{A}_{j}\right)^{-1}$, we have that

$$
\boldsymbol{\Delta} \mathbf{Y} \mathbf{p}_{j t}=(1-\beta) \mathbf{B}_{j} \mathbf{V}_{t},
$$

which could be written as:

$$
\left(\begin{array}{c}
\Delta y p_{a t} \\
\Delta y p_{j t}
\end{array}\right)=(1-\beta)\left(\begin{array}{cc}
B_{j}^{11} & B_{j}^{12} \\
B_{j}^{21} & B_{j}^{22}
\end{array}\right)\left(\begin{array}{c}
v_{a j t} \\
v_{j t}
\end{array}\right)
$$

as we wanted to show.

\section{Appendix C Data and Sources}

The table below summarizes all the raw data used on this study with their respective frequency, range and sources. 
Table 19: Raw data details

\begin{tabular}{cccc}
\hline Variable & Frequency & Data Range & Source \\
\hline Gross State Product & Yearly & $1985-2017$ & IBGE \\
State Price Index & Yearly & $1985-2017$ & IBGE \\
Population (Brazil and States) & Yearly & $2000-2019$ & IBGE \\
Retail Sales (Brazil and States) & Monthly & $2000.01-2018.12$ & IBGE \\
Consumer Price Index (IPCA) & Monthly & $2000.01-2019.12$ & IBGE \\
Taxes Collected by Brazilian Federal Government & Monthly & $2000.01-2019.12$ & Federal Revenue \\
Federal Transfers to States and Cities & Monthly & $1997.01-2019.12$ & National Treasury \\
Nominal Interest Rate (Selic) & Monthly & $2000.01-2019.12$ & BCB \\
Country Level Population & Yearly & $1962-2018$ & World Bank \\
Final consumption Expenditure (MERCOSUL) & Yearly & $1962-2018$ & World Bank \\
Country Level GDP (MERCOSUL) & Yearly & $1962-2018$ & World Bank \\
\hline
\end{tabular}

Source: Self Elaboration.

Notice that Final consumption Expenditure and Country Level GDP were collected at constant 2010 US $\$$ values. The group of MERCOSUL countries included on the database are: Argentina, Bolivia, Brazil, Chile, Colombia, Ecuador, Paraguay, Peru and Uruguay.

\section{Appendix D Crucini's (1999) Model State Estimates}

This appendix reports per state and per country results of the estimations concerning Crucinils (1999) model. Further details could be found on tables footnotes. 
Table 20: Augmented Dickey-Fuller unit root test for Brazilian state product

\begin{tabular}{|c|c|c|}
\hline & \multicolumn{2}{|c|}{ ADF Test Statistic } \\
\hline State & Level & First Difference \\
\hline Acre & -3.193 & -2.786 \\
\hline Alagoas & 2.744 & -4.705 \\
\hline Amazonas & -2.162 & -2.687 \\
\hline Amapá & -1.322 & -2.618 \\
\hline Bahia & -2.239 & -2.525 \\
\hline Ceará & 0.904 & -2.762 \\
\hline Distrito Federal & -1.420 & -2.135 \\
\hline Espírito Santo & -1.761 & -3.499 \\
\hline Goiás & -2.358 & -2.416 \\
\hline Maranhão & -0.856 & -3.232 \\
\hline Minas Gerais & -1.295 & -3.274 \\
\hline Mato Grosso do Sul & -0.784 & -2.059 \\
\hline Mato Grosso & -2.115 & -2.290 \\
\hline Pará & -2.367 & -3.563 \\
\hline Paraíba & -1.093 & -2.802 \\
\hline Pernambuco & -1.037 & -2.810 \\
\hline Piauí & 1.084 & -2.137 \\
\hline Paraná & -2.831 & -3.856 \\
\hline Rio de Janeiro & -1.955 & -2.131 \\
\hline Rio Grande do Norte & -1.599 & -3.479 \\
\hline Rondônia & -1.897 & -2.202 \\
\hline Roraima & -0.620 & -3.705 \\
\hline Rio Grande do Sul & 2.017 & -4.930 \\
\hline Santa Catarina & 0.112 & -3.411 \\
\hline Sergipe & -2.044 & -2.045 \\
\hline São Paulo & -0.195 & -2.550 \\
\hline Tocantins & 1.074 & -2.498 \\
\hline
\end{tabular}

Notes: Augmented Dickey-Fuller Test applied for Brazilian states per capita gross state product data. The test is applied at both level and first difference of data. The number of lags for the test was selected accordingly to the AIC criteria. The test on level includes both a constant and a trend, while the test on first difference does not include constant neither trend. Source: Self Elaboration. 
Table 21: Augmented Dickey-Fuller unit root test for MERCOSUL countries product

\begin{tabular}{|c|c|c|}
\hline & \multicolumn{2}{|c|}{ ADF Test Statistic } \\
\hline Country & Level & First Difference \\
\hline Argentina & -2.745 & -5.152 \\
\hline Bolivia & -1.525 & -1.718 \\
\hline Brazil & -2.079 & -2.577 \\
\hline Chile & -2.135 & -3.553 \\
\hline Colombia & -2.587 & -2.312 \\
\hline Ecuador & -2.013 & -3.228 \\
\hline Paraguay & -1.840 & -2.503 \\
\hline Peru & -1.115 & -4.210 \\
\hline Uruguay & -2.861 & -3.940 \\
\hline
\end{tabular}

Notes: Augmented Dickey-Fuller Test applied for the MERCOSUL countries per capita gross domestic product data. The test is applied at both level and first difference of data. The number of lags for the test was selected accordingly to the AIC criteria. The test on level includes both a constant and a trend, while the test on first difference does not include constant neither trend. Source: Self Elaboration. 
Table 22: AR(1) estimates for Brazilian state product

\begin{tabular}{|c|c|c|c|c|c|}
\hline State & $\theta_{j}$ & $\mathbf{s e}\left(\theta_{j}\right)$ & t-test & P-Value & Multiplier \\
\hline Acre & 0.163 & 0.173 & 0.944 & 0.352 & 1.181 \\
\hline Alagoas & -0.227 & 0.171 & -1.327 & 0.194 & 0.825 \\
\hline Amazonas & 0.606 & 0.135 & 4.476 & 0.000 & 2.316 \\
\hline Amapá & 0.269 & 0.168 & 1.602 & 0.119 & 1.337 \\
\hline Bahia & 0.116 & 0.179 & 0.645 & 0.524 & 1.122 \\
\hline Ceará & 0.135 & 0.176 & 0.763 & 0.451 & 1.144 \\
\hline Distrito Federal & 0.517 & 0.160 & 3.225 & 0.003 & 1.943 \\
\hline Espírito Santo & -0.020 & 0.174 & -0.114 & 0.910 & 0.982 \\
\hline Goiás & 0.368 & 0.166 & 2.212 & 0.034 & 1.526 \\
\hline Maranhão & 0.191 & 0.221 & 0.862 & 0.396 & 1.218 \\
\hline Minas Gerais & 0.029 & 0.174 & 0.165 & 0.870 & 1.028 \\
\hline Mato Grosso do Sul & 0.162 & 0.175 & 0.926 & 0.362 & 1.179 \\
\hline Mato Grosso & 0.371 & 0.174 & 2.132 & 0.041 & 1.535 \\
\hline Pará & 0.207 & 0.208 & 0.993 & 0.328 & 1.241 \\
\hline Paraíba & 0.280 & 0.173 & 1.622 & 0.115 & 1.356 \\
\hline Pernambuco & 0.181 & 0.176 & 1.027 & 0.312 & 1.204 \\
\hline Piauí & 0.349 & 0.179 & 1.952 & 0.060 & 1.487 \\
\hline Paraná & 0.163 & 0.172 & 0.947 & 0.351 & 1.181 \\
\hline Rio de Janeiro & 0.291 & 0.194 & 1.501 & 0.143 & 1.375 \\
\hline Rio Grande do Norte & 0.428 & 0.171 & 2.509 & 0.018 & 1.672 \\
\hline Rondônia & 0.385 & 0.162 & 2.381 & 0.024 & 1.565 \\
\hline Roraima & 0.167 & 0.172 & 0.975 & 0.337 & 1.186 \\
\hline Rio Grande do Sul & 0.156 & 0.173 & 0.899 & 0.376 & 1.171 \\
\hline Santa Catarina & 0.205 & 0.190 & 1.081 & 0.288 & 1.238 \\
\hline Sergipe & 0.447 & 0.181 & 2.472 & 0.019 & 1.723 \\
\hline São Paulo & 0.402 & 0.163 & 2.474 & 0.019 & 1.606 \\
\hline Tocantins & 0.390 & 0.178 & 2.189 & 0.037 & 1.576 \\
\hline
\end{tabular}

Notes: Estimation results of equation $\Delta y_{j t}=\theta_{j} \Delta y_{j t-1}+\epsilon_{j t}$ for Brazilian states. The first and second columns report the estimated value for $\theta_{j}$ and its standard deviation, respectively. The third and fourth columns report the statistic and P-Value of a $5 \%$ significance test of $\theta_{j}$. Finally, last column reports the multiplier value on the computation of permanent income. Source: Self Elaboration. 
Table 23: AR(1) estimates for MERCOSUL countries per capita gross domestic product

\begin{tabular}{|c|c|c|c|c|c|}
\hline Country & $\theta_{j}$ & $\operatorname{se}\left(\theta_{j}\right)$ & t-test & P-Value & Multiplier \\
\hline Argentina & 0.138 & 0.134 & 1.036 & 0.305 & 1.149 \\
\hline Bolivia & 0.804 & 0.079 & 10.140 & 0.000 & 4.060 \\
\hline Brazil & 0.584 & 0.106 & 5.508 & 0.000 & 2.210 \\
\hline Chile & 0.417 & 0.120 & 3.461 & 0.001 & 1.642 \\
\hline Colombia & 0.719 & 0.089 & 8.093 & 0.000 & 3.075 \\
\hline Ecuador & 0.468 & 0.116 & 4.032 & 0.000 & 1.781 \\
\hline Paraguay & 0.630 & 0.101 & 6.212 & 0.000 & 2.442 \\
\hline Peru & 0.496 & 0.114 & 4.352 & 0.000 & 1.870 \\
\hline Uruguay & 0.582 & 0.106 & 5.493 & 0.000 & 2.202 \\
\hline
\end{tabular}

Notes: Estimation results of equation $\Delta y_{j t}=\theta_{j} \Delta y_{j t-1}+\epsilon_{j t}$ for MERCOSUL countries. The first and second columns report the estimated value for $\theta_{j}$ and its standard deviation, respectively. The third and fourth columns report the statistic and P-Value of a $5 \%$ significance test of $\theta_{j}$. Finally, last column reports the multiplier value on the computation of permanent income. Notes: Source: Self Elaboration. 
Table 24: VAR(1) estimates for per capita Brazilian states product $\left(A^{21}\right)$

\begin{tabular}{|c|c|c|c|c|c|}
\hline & \multicolumn{5}{|c|}{$A^{21}$} \\
\hline State & Estimate & $\operatorname{se}\left(A^{21}\right)$ & t-value & P-Value & Multiplier $\left(B^{21}\right)$ \\
\hline$A C$ & 0.111 & 0.208 & 0.534 & 0.597 & 0.115 \\
\hline$A L$ & 0.605 & 0.243 & 2.493 & 0.019 & 0.385 \\
\hline$A M$ & 0.146 & 0.486 & 0.300 & 0.767 & 0.236 \\
\hline$A P$ & -0.157 & 0.248 & -0.632 & 0.532 & -0.208 \\
\hline$\overline{B A}$ & 0.572 & 0.300 & 1.909 & 0.066 & 0.626 \\
\hline$C E$ & 0.436 & 0.246 & 1.774 & 0.087 & 0.397 \\
\hline$\overline{D F}$ & 0.179 & 0.129 & 1.387 & 0.176 & -0.951 \\
\hline$E S$ & 0.620 & 0.435 & 1.425 & 0.165 & 0.452 \\
\hline$G O$ & 0.284 & 0.315 & 0.901 & 0.375 & 0.437 \\
\hline$M A$ & 0.381 & 0.327 & 1.165 & 0.254 & 0.379 \\
\hline$M G$ & 1.148 & 0.356 & 3.221 & 0.003 & 0.614 \\
\hline$M S$ & 0.381 & 0.276 & 1.377 & 0.179 & 0.357 \\
\hline$M T$ & 0.213 & 0.449 & 0.474 & 0.639 & 0.237 \\
\hline$P A$ & 0.163 & 0.241 & 0.676 & 0.505 & 0.159 \\
\hline$P B$ & 0.591 & 0.300 & 1.973 & 0.058 & 0.645 \\
\hline$P E$ & 0.983 & 0.381 & 2.582 & 0.015 & 0.542 \\
\hline$P I$ & 0.462 & 0.305 & 1.514 & 0.141 & 0.599 \\
\hline$P R$ & 0.761 & 0.397 & 1.916 & 0.065 & 0.623 \\
\hline$R J$ & 0.467 & 0.208 & 2.241 & 0.033 & 0.337 \\
\hline$R N$ & 0.640 & 0.202 & 3.172 & 0.004 & 0.495 \\
\hline$R O$ & 0.064 & 0.346 & 0.184 & 0.855 & 0.159 \\
\hline$R R$ & 0.251 & 0.168 & 1.492 & 0.147 & 0.316 \\
\hline$R S$ & -0.030 & 0.385 & -0.078 & 0.938 & -0.037 \\
\hline$S C$ & 0.074 & 0.307 & 0.243 & 0.810 & 0.090 \\
\hline$S E$ & 0.291 & 0.241 & 1.207 & 0.237 & 0.598 \\
\hline$S P$ & 0.066 & 0.611 & 0.107 & 0.915 & 0.061 \\
\hline TO & 0.216 & 0.361 & 0.598 & 0.555 & 0.443 \\
\hline
\end{tabular}

Notes: Estimated impacts of aggregate income growth lagged values on regional income from a $\operatorname{VAR}(1)$, which is denoted by $A^{21}$ on equation (12). The first and second columns report the estimated value for $A^{21}$ and its standard deviation, respectively. The third and fourth columns report the statistic and P-Value of a $5 \%$ significance test of $A^{21}$. Finally, last column reports the multiplier $\left(B^{21}\right)$ value on the computation of permanent income. Source: Self Elaboration. 
Table 25: VAR(1) estimates for per capita Brazilian states product $\left(A^{22}\right)$

\begin{tabular}{|c|c|c|c|c|c|}
\hline & \multicolumn{5}{|c|}{$A^{22}$} \\
\hline State & Estimate & $\operatorname{se}\left(A^{22}\right)$ & t-Value & P-Value & Multiplier $\left(B^{22}\right)$ \\
\hline$A C$ & 0.130 & 0.194 & 0.670 & 0.508 & 0.588 \\
\hline$A L$ & -0.416 & 0.181 & -2.298 & 0.029 & 0.680 \\
\hline$A M$ & 0.578 & 0.203 & 2.848 & 0.008 & 0.464 \\
\hline$A P$ & 0.347 & 0.211 & 1.647 & 0.110 & 0.541 \\
\hline$\overline{B A}$ & -0.197 & 0.232 & -0.847 & 0.404 & 0.754 \\
\hline$C E$ & -0.080 & 0.209 & -0.381 & 0.706 & 0.640 \\
\hline$\overline{D F}$ & 0.287 & 0.201 & 1.424 & 0.165 & 1.227 \\
\hline$E S$ & -0.281 & 0.256 & -1.096 & 0.282 & 0.613 \\
\hline$G O$ & 0.141 & 0.293 & 0.482 & 0.633 & 0.702 \\
\hline$M A$ & -0.032 & 0.195 & -0.164 & 0.871 & 0.667 \\
\hline$M G$ & -0.689 & 0.274 & -2.513 & 0.018 & 0.631 \\
\hline$M S$ & -0.006 & 0.220 & -0.027 & 0.979 & 0.623 \\
\hline$M T$ & 0.305 & 0.225 & 1.356 & 0.186 & 0.531 \\
\hline$P A$ & 0.078 & 0.180 & 0.431 & 0.669 & 0.603 \\
\hline$P B$ & 0.029 & 0.203 & 0.141 & 0.889 & 0.640 \\
\hline$P E$ & -0.556 & 0.326 & -1.706 & 0.099 & 0.615 \\
\hline$P I$ & 0.106 & 0.232 & 0.456 & 0.652 & 0.646 \\
\hline$P R$ & -0.176 & 0.248 & -0.709 & 0.484 & 0.640 \\
\hline$R J$ & -0.192 & 0.239 & -0.802 & 0.429 & 0.633 \\
\hline$R N$ & -0.050 & 0.190 & -0.265 & 0.793 & 0.615 \\
\hline$R O$ & 0.372 & 0.220 & 1.694 & 0.101 & 0.744 \\
\hline$R R$ & 0.087 & 0.186 & 0.470 & 0.642 & 0.552 \\
\hline$R S$ & 0.172 & 0.251 & 0.683 & 0.500 & 0.669 \\
\hline$S C$ & 0.114 & 0.300 & 0.381 & 0.706 & 0.660 \\
\hline$S E$ & 0.153 & 0.222 & 0.689 & 0.496 & 0.755 \\
\hline$S P$ & 0.343 & 0.498 & 0.688 & 0.497 & 0.459 \\
\hline TO & 0.258 & 0.261 & 0.986 & 0.334 & 1.329 \\
\hline
\end{tabular}

Notes: Estimated impacts of lagged regional income growth on its current value from a jointly $\operatorname{VAR}(1)$ with aggregated income growth, which is denoted by $A^{22}$ on equation (12). The first and second columns report the estimated value for $A^{22}$ and its standard deviation, respectively. The third and fourth columns report the statistic and P-Value of a $5 \%$ significance test of $A^{22}$. Finally, last column reports the multiplier value $\left(B^{22}\right)$ on the computation of permanent income. Source: Self Elaboration. 
Table 26: VAR(1) estimation for MERCOSUL country level data $\left(A^{21}\right)$

\begin{tabular}{|c|cccccc|}
\hline & \multicolumn{5}{|c|}{$A^{21}$} \\
\cline { 1 - 5 } Country & Estimate & se $\left(A^{21}\right)$ & t-Value & P-Value & Multiplier $\left(B^{21}\right)$ \\
\cline { 1 - 4 } Argentina & 0.221 & 0.177 & 1.25 & 0.217 & 0.906 \\
\cline { 1 - 1 } Bolivia & 0.115 & 0.063 & 1.828 & 0.073 & 1.135 \\
\cline { 1 - 1 } Brazil & 0.407 & 0.22 & 1.852 & 0.07 & 3.617 \\
\cline { 1 - 1 } Chile & 0.279 & 0.153 & 1.829 & 0.073 & 1.391 \\
\cline { 1 - 1 } Colombia & 0.271 & 0.094 & 2.888 & 0.006 & 1.326 \\
\cline { 1 - 1 } Ecuador & 0.354 & 0.096 & 3.688 & 0.001 & 1.467 \\
\cline { 1 - 1 } Paraguay & 0.337 & 0.12 & 2.816 & 0.007 & 1.872 \\
\cline { 1 - 1 } Peru & 0.205 & 0.146 & 1.409 & 0.165 & 1.297 \\
\cline { 1 - 1 } Uruguay & 0.299 & 0.124 & 2.417 & 0.019 & 1.775 \\
\hline
\end{tabular}

Notes: Estimated impacts of aggregate income growth lagged values on regional income from a $\operatorname{VAR}(1)$, which is denoted by $A^{21}$ on equation (12). The first and second columns report the estimated value for $A^{21}$ and its standard deviation, respectively. The third and fourth columns report the statistic and P-Value of a $5 \%$ significance test of $A^{21}$. Finally, last column reports the multiplier value $\left(B^{21}\right)$ on the computation of permanent income. Source: Self Elaboration.

Table 27: VAR(1) estimation for MERCOSUL country level data $\left(A^{22}\right)$

\begin{tabular}{|c|cccccc|}
\hline & \multicolumn{5}{|c|}{$A^{22}$} \\
\cline { 1 - 5 } Country & Estimate & SE & t-Value & P-Value & Multiplier $\left(B^{22}\right)$ \\
\cline { 1 - 1 } Argentina & 0.044 & 0.152 & 0.288 & 0.774 & -2.414 \\
\cline { 1 - 1 } Bolivia & 0.702 & 0.092 & 7.626 & 0.000 & -6.007 \\
\cline { 1 - 1 } Brazil & 0.191 & 0.241 & 0.792 & 0.432 & -9.054 \\
\cline { 1 - 1 } Chile & 0.308 & 0.135 & 2.279 & 0.027 & -2.981 \\
\cline { 1 - 1 } Colombia & 0.383 & 0.149 & 2.566 & 0.013 & -2.16 \\
\cline { 1 - 1 } Ecuador & 0.177 & 0.135 & 1.315 & 0.194 & -2.242 \\
\cline { 1 - 1 } Paraguay & 0.384 & 0.134 & 2.869 & 0.006 & -3.567 \\
\cline { 1 - 1 } Peru & 0.414 & 0.133 & 3.117 & 0.003 & -4.387 \\
\cline { 1 - 1 } Uruguay & 0.428 & 0.125 & 3.421 & 0.001 & -4.006 \\
\hline
\end{tabular}

Notes: Estimated impacts of lagged country income growth on its current value from a jointly VAR(1) with aggregated income growth, which is denoted by $A^{22}$ on equation (12). The first and second columns report the estimated value for $A^{22}$ and its standard deviation, respectively. The third and fourth columns report the statistic and P-Value of a $5 \%$ significance test of $A^{22}$. Finally, last column reports the multiplier value $\left(B^{22}\right)$ on the computation of permanent income. Source: Self Elaboration. 
Table 28: Degree of risk sharing estimates assuming a RW as income process for Brazilian states

\begin{tabular}{|c|c|c|c|c|c|c|}
\hline States & $\lambda$ & $\operatorname{sd}(\lambda)$ & t-test $(\lambda=0)$ & t-test $(\lambda=1)$ & $R^{2}$ & F-test \\
\hline$A C$ & 1.420 & 0.201 & 7.052 & 2.087 & 0.751 & 0.591 \\
\hline$A L$ & 1.346 & 0.228 & 5.895 & 1.515 & 0.787 & 0.741 \\
\hline$A M$ & 0.811 & 0.222 & 3.657 & -0.855 & 0.695 & 0.664 \\
\hline$A P$ & 0.637 & 0.202 & 3.151 & -1.799 & 0.551 & 6.519 \\
\hline$B A$ & 0.951 & 0.244 & 3.895 & -0.202 & 0.907 & 3.600 \\
\hline$C E$ & 1.168 & 0.239 & 4.887 & 0.704 & 0.934 & 0.268 \\
\hline$D F$ & 0.619 & 0.211 & 2.936 & -1.808 & 0.667 & 0.659 \\
\hline$E S$ & 0.876 & 0.197 & 4.452 & -0.631 & 0.771 & 0.491 \\
\hline$G O$ & 0.926 & 0.228 & 4.060 & -0.324 & 0.745 & 0.008 \\
\hline$M A$ & 1.355 & 0.247 & 5.495 & 1.439 & 0.788 & 7.385 \\
\hline$M G$ & 0.581 & 0.228 & 2.554 & -1.841 & 0.662 & 0.002 \\
\hline$M S$ & 0.914 & 0.184 & 4.956 & -0.467 & 0.685 & 0.000 \\
\hline$M T$ & 0.400 & 0.184 & 2.170 & -3.256 & 0.543 & 0.230 \\
\hline$P A$ & 0.812 & 0.201 & 4.042 & -0.934 & 0.818 & 0.023 \\
\hline$P B$ & 1.263 & 0.225 & 5.609 & 1.168 & 0.681 & 1.097 \\
\hline$P E$ & 1.102 & 0.278 & 3.967 & 0.366 & 0.937 & 0.048 \\
\hline$P I$ & 0.719 & 0.228 & 3.151 & -1.228 & 0.415 & 0.000 \\
\hline$P R$ & 0.516 & 0.195 & 2.641 & -2.474 & 0.628 & 0.147 \\
\hline$R J$ & 0.604 & 0.222 & 2.722 & -1.784 & 0.846 & 0.332 \\
\hline$R N$ & 1.167 & 0.205 & 5.695 & 0.814 & 0.830 & 0.662 \\
\hline$R O$ & 0.906 & 0.217 & 4.176 & -0.431 & 0.568 & 6.098 \\
\hline$R R$ & 0.584 & 0.203 & 2.875 & -2.048 & 0.227 & 1.958 \\
\hline$R S$ & 0.522 & 0.184 & 2.841 & -2.596 & 0.638 & 0.044 \\
\hline$S C$ & 0.465 & 0.201 & 2.313 & -2.665 & 0.556 & 1.527 \\
\hline$S E$ & 0.933 & 0.233 & 4.011 & -0.287 & 0.632 & 0.376 \\
\hline$S P$ & 0.593 & 0.248 & 2.397 & -1.643 & 0.753 & 1.294 \\
\hline TO & 1.712 & 0.225 & 7.604 & 3.161 & 0.579 & 8.108 \\
\hline
\end{tabular}

Notes: Brazilian states estimation results of equation $\Delta c_{j t}=\lambda_{j} \Delta c_{a t}+\left(1-\lambda_{j}\right) \Delta y \hat{p}_{j t}+\epsilon_{j t}$ when permanent income update is computed assuming an RW process for income growth. The first and second columns report the estimated value for $\lambda$ and its standard deviation, respectively. The third and fourth columns report the t-statistics to test if $\lambda=0$ and $\lambda=1$, respectively. The fifth column presents the $R^{2}$ of the regressions, while the last reports the F-test statistic for the restriction that the regression coefficients sum to 1. Source: Self Elaboration. 
Table 29: Degree of risk sharing estimates assuming an AR(1) as income process for Brazilian states

\begin{tabular}{|c|c|c|c|c|c|c|}
\hline States & $\lambda$ & $\operatorname{sd}(\lambda)$ & t-test $(\lambda=0)$ & t-test $(\lambda=1)$ & $R^{2}$ & F-test \\
\hline$A C$ & 1.337 & 0.193 & 6.924 & 1.744 & 0.733 & 1.604 \\
\hline$A L$ & 1.393 & 0.232 & 6.009 & 1.695 & 0.797 & 0.083 \\
\hline$A M$ & 0.840 & 0.121 & 6.956 & -1.327 & 0.717 & 0.123 \\
\hline$A P$ & 0.551 & 0.183 & 3.009 & -2.453 & 0.588 & 6.430 \\
\hline$B A$ & 0.937 & 0.239 & 3.915 & -0.263 & 0.908 & 3.446 \\
\hline$C E$ & 1.181 & 0.234 & 5.045 & 0.773 & 0.937 & 0.322 \\
\hline$D F$ & 0.637 & 0.196 & 3.253 & -1.850 & 0.673 & 0.033 \\
\hline$E S$ & 0.872 & 0.200 & 4.369 & -0.639 & 0.771 & 0.536 \\
\hline$G O$ & 0.991 & 0.207 & 4.792 & -0.045 & 0.742 & 0.242 \\
\hline$M A$ & 1.287 & 0.236 & 5.464 & 1.219 & 0.778 & 8.376 \\
\hline$M G$ & 0.585 & 0.227 & 2.571 & -1.826 & 0.661 & 0.013 \\
\hline$M S$ & 0.938 & 0.175 & 5.364 & -0.352 & 0.682 & 0.055 \\
\hline$M T$ & 0.548 & 0.130 & 4.229 & -3.487 & 0.574 & 0.040 \\
\hline$P A$ & 0.833 & 0.192 & 4.327 & -0.870 & 0.814 & 0.038 \\
\hline$P B$ & 1.209 & 0.214 & 5.665 & 0.981 & 0.675 & 1.440 \\
\hline$P E$ & 1.091 & 0.282 & 3.872 & 0.323 & 0.936 & 0.021 \\
\hline$P I$ & 0.838 & 0.184 & 4.549 & -0.878 & 0.394 & 0.223 \\
\hline$P R$ & 0.563 & 0.185 & 3.044 & -2.363 & 0.600 & 0.707 \\
\hline$R J$ & 0.586 & 0.235 & 2.494 & -1.764 & 0.845 & 0.008 \\
\hline$R N$ & 1.178 & 0.202 & 5.836 & 0.883 & 0.833 & 0.320 \\
\hline$R O$ & 0.934 & 0.167 & 5.600 & -0.397 & 0.568 & 3.317 \\
\hline$R R$ & 0.571 & 0.199 & 2.867 & -2.151 & 0.232 & 1.389 \\
\hline$R S$ & 0.565 & 0.174 & 3.250 & -2.499 & 0.620 & 0.057 \\
\hline$S C$ & 0.470 & 0.194 & 2.417 & -2.726 & 0.577 & 0.704 \\
\hline$S E$ & 0.972 & 0.214 & 4.536 & -0.132 & 0.630 & 0.036 \\
\hline$S P$ & 0.690 & 0.218 & 3.174 & -1.424 & 0.728 & 0.066 \\
\hline TO & 1.294 & 0.173 & 7.498 & 1.702 & 0.524 & 11.385 \\
\hline
\end{tabular}

Notes: Brazilian states estimation results of equation $\Delta c_{j t}=\lambda_{j} \Delta c_{a t}+\left(1-\lambda_{j}\right) \Delta y \hat{p}_{j t}+\epsilon_{j t}$ when permanent income update is computed assuming an $\mathrm{AR}(1)$ process for income growth. The first and second columns report the estimated value for $\lambda$ and its standard deviation, respectively. The third and fourth columns report the t-statistics to test if $\lambda=0$ and $\lambda=1$, respectively. The fifth column presents the $R^{2}$ of the regressions, while the last reports the F-test statistic for the restriction that the regression coefficients sum to 1. Source: Self Elaboration. 
Table 30: Degree of Risk sharing Estimates assuming a VAR(1) as income process for Brazilian states

\begin{tabular}{|c|c|c|c|c|c|c|}
\hline States & $\lambda$ & $\operatorname{sd}(\lambda)$ & t-test $(\lambda=0)$ & t-test $(\lambda=1)$ & $R^{2}$ & F-test \\
\hline$A C$ & 1.404 & 0.192 & 7.302 & 2.103 & 0.756 & 0.099 \\
\hline$A L$ & 1.313 & 0.230 & 5.697 & 1.357 & 0.781 & 1.527 \\
\hline$A M$ & 0.973 & 0.191 & 5.081 & -0.144 & 0.681 & 0.072 \\
\hline$A P$ & 0.965 & 0.170 & 5.661 & -0.206 & 0.510 & 11.705 \\
\hline$B A$ & 0.992 & 0.233 & 4.253 & -0.035 & 0.906 & 1.100 \\
\hline$C E$ & 1.173 & 0.223 & 5.255 & 0.775 & 0.938 & 2.576 \\
\hline$D F$ & 0.662 & 0.200 & 3.319 & -1.692 & 0.659 & 0.261 \\
\hline$E S$ & 0.905 & 0.219 & 4.137 & -0.434 & 0.767 & 1.514 \\
\hline$G O$ & 0.983 & 0.214 & 4.598 & -0.080 & 0.742 & 0.398 \\
\hline$M A$ & 1.396 & 0.230 & 6.078 & 1.723 & 0.809 & 4.409 \\
\hline$M G$ & 0.620 & 0.222 & 2.793 & -1.711 & 0.646 & 0.189 \\
\hline$M S$ & 0.923 & 0.203 & 4.547 & -0.378 & 0.683 & 0.008 \\
\hline$M T$ & 0.643 & 0.198 & 3.256 & -1.804 & 0.414 & 5.795 \\
\hline$P A$ & 0.843 & 0.195 & 4.312 & -0.804 & 0.812 & 0.117 \\
\hline$P B$ & 1.308 & 0.221 & 5.917 & 1.394 & 0.692 & 0.428 \\
\hline$P E$ & 1.082 & 0.230 & 4.700 & 0.355 & 0.937 & 0.000 \\
\hline$P I$ & 0.958 & 0.221 & 4.325 & -0.191 & 0.372 & 2.034 \\
\hline$P R$ & 0.550 & 0.205 & 2.689 & -2.200 & 0.572 & 0.826 \\
\hline$R J$ & 0.677 & 0.211 & 3.216 & -1.535 & 0.814 & 0.880 \\
\hline$R N$ & 1.211 & 0.212 & 5.710 & 0.996 & 0.839 & 1.426 \\
\hline$R O$ & 1.128 & 0.202 & 5.599 & 0.637 & 0.572 & 3.066 \\
\hline$R R$ & 0.876 & 0.202 & 4.337 & -0.614 & 0.186 & 0.061 \\
\hline$R S$ & 0.570 & 0.184 & 3.104 & -2.343 & 0.600 & 0.739 \\
\hline$S C$ & 0.530 & 0.193 & 2.738 & -2.431 & 0.515 & 2.478 \\
\hline$S E$ & 1.042 & 0.221 & 4.715 & 0.190 & 0.631 & 0.136 \\
\hline$S P$ & 0.863 & 0.147 & 5.874 & -0.930 & 0.686 & 3.109 \\
\hline TO & 1.266 & 0.186 & 6.821 & 1.435 & 0.518 & 12.226 \\
\hline
\end{tabular}

Notes: Brazilian states estimation results of equation $\Delta c_{j t}=\lambda_{j} \Delta c_{a t}+\left(1-\lambda_{j}\right) \Delta y \hat{p}_{j t}+\epsilon_{j t}$ when permanent income update is computed assuming an $\operatorname{VAR}(1)$ process for income growth. The first and second columns report the estimated value for $\lambda$ and its standard deviation, respectively. The third and fourth columns report the t-statistics to test if $\lambda=0$ and $\lambda=1$, respectively. The fifth column presents the $R^{2}$ of the regressions, while the last reports the F-test statistic for the restriction that the regression coefficients sum to 1. Source: Self Elaboration. 
Table 31: Degree of Risk sharing Estimates assuming a RW as income process for MERCOSUL countries

\begin{tabular}{|c|c|c|c|c|c|c|}
\hline Country & $\lambda$ & $\operatorname{sd}(\lambda)$ & t-test $(\lambda=0)$ & t-test $(\lambda=1)$ & $R^{2}$ & F-test \\
\hline Argentina & 0.068 & 0.074 & 0.910 & -12.562 & 0.852 & 4.485 \\
\hline Bolivia & 0.320 & 0.118 & 2.716 & -5.777 & 0.576 & 2.327 \\
\hline Brazil & 0.269 & 0.097 & 2.762 & -7.522 & 0.525 & 0.854 \\
\hline Chile & 0.027 & 0.077 & 0.346 & -12.622 & 0.690 & 0.372 \\
\hline Colombia & 0.239 & 0.165 & 1.451 & -4.621 & 0.673 & 0.189 \\
\hline Ecuador & 0.211 & 0.109 & 1.931 & -7.215 & 0.525 & 1.154 \\
\hline Paraguay & 0.443 & 0.109 & 4.071 & -5.112 & 0.382 & 2.708 \\
\hline Peru & -0.037 & 0.088 & -0.418 & -11.750 & 0.844 & 0.016 \\
\hline Uruguay & 0.021 & 0.113 & 0.190 & -8.668 & 0.768 & 2.686 \\
\hline
\end{tabular}

Notes: MERCOSUL countries estimation results of equation $\Delta c_{j t}=\lambda_{j} \Delta c_{a t}+\left(1-\lambda_{j}\right) \Delta y \hat{p}_{j t}+\epsilon_{j t}$ when permanent income update is computed assuming an RW process for income growth. The first and second columns report the estimated value for $\lambda$ and its standard deviation, respectively. The third and fourth columns report the t-statistics to test if $\lambda=0$ and $\lambda=1$, respectively. The fifth column presents the $R^{2}$ of the regressions, while the last reports the F-test statistic for the restriction that the regression coefficients sum to 1. Source: Self Elaboration.

Table 32: Degree of Risk sharing Estimates assuming a AR(1) as income process for MERCOSUL countries

\begin{tabular}{|c|c|c|c|c|c|c|}
\hline Country & $\lambda$ & $\operatorname{sd}(\lambda)$ & t-test $(\lambda=0)$ & t-test $(\lambda=1)$ & $R^{2}$ & F-test \\
\hline Argentina & 0.127 & 0.080 & 1.586 & -10.886 & 0.840 & 3.000 \\
\hline Bolivia & 0.558 & 0.055 & 10.062 & -7.985 & 0.122 & 10.793 \\
\hline Brazil & 0.425 & 0.058 & 7.325 & -9.916 & 0.392 & 1.676 \\
\hline Chile & 0.321 & 0.059 & 5.473 & -11.559 & 0.493 & 0.049 \\
\hline Colombia & 0.498 & 0.072 & 6.904 & -6.960 & 0.438 & 2.534 \\
\hline Ecuador & 0.383 & 0.085 & 4.503 & -7.259 & 0.376 & 0.227 \\
\hline Paraguay & 0.542 & 0.059 & 9.172 & -7.757 & 0.171 & 3.022 \\
\hline Peru & 0.364 & 0.059 & 6.206 & -10.824 & 0.613 & 0.107 \\
\hline Uruguay & 0.430 & 0.059 & 7.276 & -9.632 & 0.624 & 3.077 \\
\hline
\end{tabular}

Notes: MERCOSUL countries estimation results of equation $\Delta c_{j t}=\lambda_{j} \Delta c_{a t}+\left(1-\lambda_{j}\right) \Delta y \hat{p}_{j t}+\epsilon_{j t}$ when permanent income update is computed assuming an $\mathrm{AR}(1)$ process for income growth. The first and second columns report the estimated value for $\lambda$ and its standard deviation, respectively. The third and fourth columns report the t-statistics to test if $\lambda=0$ and $\lambda=1$, respectively. The fifth column presents the $R^{2}$ of the regressions, while the last reports the F-test statistic for the restriction that the regression coefficients sum to 1. Source: Self Elaboration. 
Table 33: Degree of Risk sharing Estimates assuming a VAR(1) as income process for MERCOSUL countries

\begin{tabular}{|c|c|c|c|c|c|c|}
\hline Country & $\lambda$ & $\operatorname{sd}(\lambda)$ & t-test $(\lambda=0)$ & t-test $(\lambda=1)$ & $R^{2}$ & F-test \\
\hline Argentina & 0.773 & 0.032 & 24.494 & -7.205 & 0.777 & 34.293 \\
\hline Bolivia & 0.613 & 0.034 & 17.781 & -11.221 & 0.093 & 16.332 \\
\hline Brazil & 0.649 & 0.019 & 34.585 & -18.670 & 0.321 & 9.980 \\
\hline Chile & 0.745 & 0.029 & 25.752 & -8.792 & 0.534 & 4.705 \\
\hline Colombia & 0.642 & 0.086 & 7.485 & -4.169 & 0.293 & 11.524 \\
\hline Ecuador & 0.734 & 0.062 & 11.922 & -4.327 & 0.328 & 6.098 \\
\hline Paraguay & 0.653 & 0.039 & 16.779 & -8.918 & 0.209 & 8.682 \\
\hline Peru & 0.686 & 0.021 & 32.155 & -14.725 & 0.617 & 6.533 \\
\hline Uruguay & 0.702 & 0.028 & 24.817 & -10.539 & 0.709 & 0.000 \\
\hline
\end{tabular}

Notes: MERCOSUL countries estimation results of equation $\Delta c_{j t}=\lambda_{j} \Delta c_{a t}+\left(1-\lambda_{j}\right) \Delta y \hat{p}_{j t}+\epsilon_{j t}$ when permanent income update is computed assuming an $\operatorname{VAR}(1)$ process for income growth. The first and second columns report the estimated value for $\lambda$ and its standard deviation, respectively. The third and fourth columns report the t-statistics to test if $\lambda=0$ and $\lambda=1$, respectively. The fifth column presents the $R^{2}$ of the regressions, while the last reports the F-test statistic for the restriction that the regression coefficients sum to 1. Source: Self Elaboration. 